\title{
Comparative and functional genomics of the Lactococcus lactis taxon; insights into evolution and niche adaptation
}

\author{
Philip Kelleher $^{1} \mathbb{D}$, Francesca Bottacini ${ }^{2}$, Jennifer Mahony ${ }^{1,2}$, Kieran N. Kilcawley ${ }^{3}$ and Douwe van Sinderen ${ }^{1,2^{*}}$
}

\begin{abstract}
Background: Lactococcus lactis is among the most widely studied lactic acid bacterial species due to its long history of safe use and economic importance to the dairy industry, where it is exploited as a starter culture in cheese production.

Results: In the current study, we report on the complete sequencing of 16 L. lactis subsp. lactis and L. lactis subsp. cremoris genomes. The chromosomal features of these $16 \mathrm{~L}$. lactis strains in conjunction with 14 completely sequenced, publicly available lactococcal chromosomes were assessed with particular emphasis on discerning the $L$. lactis subspecies division, evolution and niche adaptation. The deduced pan-genome of L. lactis was found to be closed, indicating that the representative data sets employed for this analysis are sufficient to fully describe the genetic diversity of the taxon.

Conclusions: Niche adaptation appears to play a significant role in governing the genetic content of each L. lactis subspecies, while (differential) genome decay and redundancy in the dairy niche is also highlighted.
\end{abstract}

Keywords: Lactococcus lactis, Genomics, SMRT sequencing, Pan-genome, Niche adaptation

\section{Background}

Lactococcus lactis is a Gram positive, catalase-negative, non-motile and coccoid bacterium [1]. L. lactis has a long history of safe use in the fermented food industry and as such enjoys a so-called "GRAS" (Generally Regarded as Safe) status. Lactococcal strains are particularly important to the dairy industry, where they are employed as starter cultures for cheese production. L. lactis has four component subspecies, two of which are routinely employed in the dairy fermentation sector, i.e. subspecies (subsp.) cremoris and subsp. lactis (and a biovariant; subsp. lactis biovar diacetylactis, which distinguishes itself based on citrate metabolism, see also below). The two remaining $L$. lactis subspecies, i.e. L. lactis subsp. hordniae isolated from the leafhopper Hordnia circellata [2], and L. lactis subsp. tructae isolated from brown trout, Salmo trutta [3], are considerably under-represented in both biological

\footnotetext{
* Correspondence: d.vansinderen@ucc.ie

${ }^{1}$ School of Microbiology, University College Cork, Cork, Ireland

${ }^{2}$ Alimentary Pharmabiotic Centre, University College Cork, Cork, Ireland

Full list of author information is available at the end of the article
}

and genomic studies compared to their dairy-associated counterparts.

Genetically, a typical $L$. lactis chromosome ranges in size from $\sim 2.2$ to $2.6 \mathrm{Mb}$, often accompanied by a rich plasmid complement [4] and multiple integrated (remnant) prophages [5]. Reductive evolution and genome decay have previously been reported in 'domesticated', dairy L. lactis strains, particularly those belonging to subspecies cremoris [6, 7]. Niche adaptation by lactococcal strains has been investigated most thoroughly in relation to the dairy environment. In this particular niche, strain adaptations appear to be mainly plasmid-encoded and two examples of this are lactose and citrate utilisation. Lactose utilisation in L. lactis is performed via the lac operon, which consists of the lacABCDEFGX genes and which is regulated by the repressor lacR $[8,9]$. Citrate metabolism by citratepositive $\left(\mathrm{Cit}^{+}\right)$lactococci is mediated by the citQRP operon [10]. The classification of $\mathrm{Cit}^{+}$lactococci as L. lactis subsp. lactis biovar diacetylactis has led to confusion as plasmid-encoded characteristics can be transferred from one strain to another and may lead to incorrect 
classification based on phenotype [11], highlighting the importance of genome sequencing for the correct characterisation of members of this taxon.

The advent of modern sequencing technologies has made whole genome analysis more accessible, and as a result there are now 84 lactococcal assemblies publicly available in the NCBI (National Centre for Biotechnology Information) database, 14 of which represent complete genome sequences including the two prototypical stains L. lactis subsp. lactis IL1403 [12] and L. lactis subsp. cremoris MG1363 [13]. To date a number of comparative genome studies have been conducted and have provided novel insights into lipolysis [14], prophage $[5,6]$, proteolysis [15], taxonomy [16] and niche adaptation functions of these strains [17].

In the current study we applied one of the latest sequencing technologies, Single-Molecule-Real-Time (SMRT) sequencing developed by Pacific Biosciences $[18,19]$ to contribute a further 16 complete lactococcal genomes to the public database. The increased dataset of complete lactococcal genomic sequences allows for the investigation of the corresponding pan-genome, which when closed defines the total number of genes encoded in the L. lactis taxon [20-22]. Furthermore, phylogeny, core and non-core genes, metabolism and niche-specific adaptations in terms of the total genetic content of the taxon were examined.

\section{Results}

\section{General genome features}

In this study, the chromosomal features of $30 \mathrm{~L}$. lactis strains were assessed, 18 of which belong to subspecies lactis and a further 12 to subspecies cremoris based on phylogenetic analysis of 16S RNA. For all selected strains, complete genome assemblies were available, of which 14 were obtained from the NCBI (National Centre for Biotechnology Information) database, while the remaining 16 were sequenced as part of the current study using the SMRT sequencing approach (Table 1). Although the NCBI database contains in total 84 L. lactis genome assemblies, only those, which are fully finished (i.e. present in the data base as a single chromosomal contig), were selected for this project due to the inherent limitations of draft assemblies. Briefly, the order and orientation of contigs of such draft assemblies remains unresolved and the differentiation between traits, which are verified to be chromosomally-encoded versus plasmid-encoded, is not possible particularly when one considers plasmid integration events. Most notable, however, is the finite nature of a finished genome which facilitates the comparison of the full genetic content of a strain rather than most of the genetic content, whereas in the case of a draft genome the likelihood of error from missing genes or incorrect copy number is significantly higher $[23,24]$.
The $30 \mathrm{~L}$. lactis strains included in this study encompass six different ecological niches; dairy, plant, meat, fermented foods, human isolate (this is a vaginal isolate of a healthy woman) and a strain isolated from a sink drain, with the vast majority isolated from the dairy environment, most notably for the production of cheese (Table 1). Comparison of the 30 lactococcal genomes established an average chromosome length of $2.428 \mathrm{Mbp}$ from a range of 2.250-2.589 Mbp, where it should be noted that in general the genomes of subsp. lactis are larger than their subsp. cremoris counterparts (Table 2). Genomes belonging to the subsp. cremoris contain a higher proportion of pseudogenes and insertion sequence (IS) elements/transposons, indicative of transpositions and (associated) genome decay within the subsp. cremoris genome. A defining characteristic of both subspecies is evident in the number of plasmids within each strain. L. lactis carries many niche-specific adaptations within its plasmid complement, particularly for the dairy environment, such as lactose utilisation and casein utilisation, and this is evident in the larger plasmid complement observed for subsp. cremoris strains predominantly isolated from the dairy niche. A substantial proportion of the observed genomic diversity is due to a variable number of integrated prophage elements (Table 2).

General feature extractions conducted on each of the chromosomes generated an overall average of 2344 predicted CDS (Coding Sequences) per chromosome form a range of 1947 to 2643 CDSs of which $77.6 \%$ can be functionally assigned using BLAST (Basic Local Alignment Search Tool) based on in silico predictions, while the remaining $22.4 \%$ are assigned as hypothetical proteins (Table 2).

\section{Phylogenetic analysis and genome synteny}

To investigate the phylogenetic relationship between the selected lactococcal isolates, a multifaceted approach was employed. Firstly, the 30 genomes were aligned based on 16S rRNA sequences with Streptococcus thermophilus used as an out-group to root the phylogenetic tree, resulting in a clear division into two major clades that correspond to the subsp. lactis and subsp. cremoris division (Fig. 1a). In order to improve the phylogenetic resolution of the analysis, a second approach was employed by constructing a phylogenetic supertree of 596 conserved orthologous proteins using an approach that has previously been applied to other species [22, 25]. The conserved orthologues were selected based on all-against-all reciprocal BLASTP analysis with an evalue cut-off of 0.0001 and MCL (Markov Clustering) in order to identify single-copy genes conserved across all 31 (30 L. lactis plus $S$. thermophilus out-group) genomes in the phylogenetic analysis (Fig. 1b). The generated 
Table 1 Lactococcal representative strains used in this study

\begin{tabular}{|c|c|c|c|c|c|}
\hline Strain name & Genbank accession & Ecological niche & Sequencing technology & Year & Citation \\
\hline \multicolumn{6}{|l|}{ subsp. lactis } \\
\hline$\| 1403$ & AE005176 & Dairy isolate & Sanger & 2001 & [12] \\
\hline KF147 & CP001834 & Plant isolate & 454-pyrosequencing \& Illumina & 2009 & {$[65]$} \\
\hline CV56 & CP002365 & Human isolate & 454-pyrosequencing & 2011 & {$[66]$} \\
\hline $10-1$ & AP012281 & Drain water & Sanger & 2012 & {$[67]$} \\
\hline KLDS 4.0325 & СР006766 & Koumiss & Illumina & 2013 & {$[68]$} \\
\hline NCDO 2118 & CP009054 & Frozen peas & SOLiD, Ion PGM \& Ion Torrent PGM & 2014 & [69] \\
\hline $\mathrm{SO}$ & CP010050 & Dairy isolate & Ion Torrent PGM & 2014 & [70] \\
\hline Al06 & CP009472 & Açaí palm & 454-pyrosequencing & 2014 & {$[26]$} \\
\hline 184 & CP015895 & Dairy isolate & PacBio SMRT & 2016 & $* *$ \\
\hline 229 & CP015896 & Dairy isolate & PacBio SMRT & 2016 & $* *$ \\
\hline 275 & CP015897 & Dairy isolate & PacBio SMRT & 2016 & $* *$ \\
\hline UC06 & CP015902 & Dairy isolate & PacBio SMRT & 2016 & $* *$ \\
\hline UC08 & СР015903 & Fermented meat & PacBio SMRT & 2016 & $* *$ \\
\hline UC11 & СР015904 & Fermented meat & PacBio SMRT & 2016 & $* *$ \\
\hline UC063 & СР015905 & Dairy isolate & PacBio SMRT & 2016 & $* *$ \\
\hline UC77 & СР015906 & Dairy isolate & PacBio SMRT & 2016 & $* *$ \\
\hline UL8 & СР015908 & Dairy isolate & PacBio SMRT & 2016 & $* *$ \\
\hline $\mathrm{C} 10$ & СР015898 & Dairy isolate & PacBio SMRT & 2016 & $* *$ \\
\hline \multicolumn{6}{|l|}{ subsp. cremoris } \\
\hline SK11 & CP000425 & Dairy isolate & Sanger & 2006 & [7] \\
\hline MG1363 & AM406671 & Dairy isolate & Sanger & 2007 & [13] \\
\hline NZ9000 & CP002094 & Laboratory strain & Illumina & 2010 & [71] \\
\hline A76 & CP003132 & Dairy isolate & Sanger & 2011 & {$[72]$} \\
\hline UC509.9 & CP003157 & Dairy isolate & 454-pyrosequencing \& Illumina & 2012 & [6] \\
\hline KW2 & СР004884 & Dairy isolate & 454-pyrosequencing & 2013 & [73] \\
\hline 158 & CP015894 & Dairy isolate & PacBio SMRT & 2016 & $* *$ \\
\hline UC109 & СР015907 & Dairy isolate & PacBio SMRT & 2016 & $* *$ \\
\hline $\mathrm{JM1}$ & CP015899 & Dairy isolate & PacBio SMRT & 2016 & $* *$ \\
\hline$J M 2$ & СР015900 & Dairy isolate & PacBio SMRT & 2016 & $* *$ \\
\hline JM3 & СР015901 & Dairy isolate & PacBio SMRT & 2016 & ** \\
\hline JM4 & СР015909 & Dairy isolate & PacBio SMRT & 2016 & $* *$ \\
\hline
\end{tabular}

** Sequenced in the framework of this study

supertree displays the same bifurcation observed for the 16S rRNA analysis (Fig. 1a \& b), substantiating this clear genomic differentiation between the two subspecies. The most notable difference in the lactococcal supertree was that the majority of subclades correspond to niche specificity. Dairy isolates of subsp. cremoris cluster together into one clade, distinct from $L$. lactis KW2 isolated from fermented corn, while L. lactis NZ9000 and its parent strain $L$. lactis MG1363, which originated from the dairy niche formed their own clade. Dairy isolates of subsp. lactis also grouped together, with the exception of $L$. lactis UC06 and L. lactis SO. Furthermore, subsp. lactis isolates from meat and fermented foods, each formed separate clades (Fig. 1b).

The deduced tree is also indicative of a unique allelic type for CDSs from subsp. lactis isolates in comparison to those from subsp. cremoris isolates, and is in agreement with the described differences in average nucleotide identity and tetranucleotide frequency correlation coefficients between the two subspecies [16]. To investigate the unique allelic types of the two subspecies, a subset of individual highly conserved housekeeping genes, i.e. those required for the maintenance of basic cellular functions, from each of the genomes were aligned independently (involving the following genes: $\operatorname{rec} X, \operatorname{ss} b A, \operatorname{rec} Q, \operatorname{rad} A$, and 
Table 2 General genome features of thirty representative L. lactis genomes

\begin{tabular}{|c|c|c|c|c|c|c|c|c|c|c|c|}
\hline Strain & $\begin{array}{l}\text { Genome } \\
\text { length (Mbp) }\end{array}$ & CDS & $\begin{array}{l}\text { tRNA } \\
\text { features }\end{array}$ & $\begin{array}{l}\text { rRNA } \\
\text { features }\end{array}$ & $\begin{array}{l}\text { Hypothetical } \\
\text { proteins \% }\end{array}$ & $\begin{array}{l}\text { Assigned } \\
\text { function \% }\end{array}$ & $\begin{array}{l}\text { Pseudo } \\
\text { genes }\end{array}$ & $\begin{array}{l}\text { IS elements/ } \\
\text { transposases }\end{array}$ & Prophage & Plasmids & GC \% \\
\hline \multicolumn{12}{|l|}{ L. lactis subsp. lactis } \\
\hline 184 & 2343 & 2312 & 51 & 15 & 19.6 & 80.4 & 15 & 59 & $2 \ln ^{a} 6 \operatorname{Re}^{b}$ & 3 & 35.16 \\
\hline 229 & 2455 & 2541 & 56 & 15 & 20.2 & 79.8 & 15 & 94 & $4 \ln 3 \operatorname{Re}$ & 5 & 35.19 \\
\hline 275 & 2496 & 2418 & 58 & 18 & 20.2 & 79.8 & 14 & 43 & $3 \ln 6 \operatorname{Re}$ & 4 & 35.49 \\
\hline UC06 & 2571 & 2472 & 61 & 18 & 21.7 & 78.3 & 8 & 35 & $2 \ln 3 \operatorname{Re}$ & 3 & 35.26 \\
\hline UC08 & 2382 & 2246 & 62 & 18 & 20.0 & 80.0 & 14 & 18 & $2 \operatorname{Re}$ & 3 & 35.00 \\
\hline UC11 & 2382 & 2237 & 60 & 19 & 20.0 & 80.0 & 16 & 17 & $2 \mathrm{Re}$ & 6 & 35.00 \\
\hline UC063 & 2393 & 2361 & 59 & 18 & 19.2 & 80.8 & 14 & 59 & $3 \ln 5 \operatorname{Re}$ & 5 & 35.32 \\
\hline UC77 & 2538 & 2541 & 66 & 21 & 19.0 & 81.0 & 12 & 96 & $5 \ln 3 \operatorname{Re}$ & 2 & 35.26 \\
\hline UL8 & 2422 & 2405 & 59 & 17 & 18.5 & 81.5 & 13 & 56 & $3 \ln 7 \operatorname{Re}$ & 3 & 35.29 \\
\hline $\mathrm{C} 10$ & 2336 & 2294 & 50 & 15 & 17.7 & 82.3 & 21 & 53 & $5 \ln 3 \operatorname{Re}$ & 1 & 35.30 \\
\hline IL1403 & 2366 & 2267 & 62 & 18 & 21.0 & 79.0 & 43 & 43 & $3 \ln 3 \operatorname{Re}$ & - & 35.33 \\
\hline KLDS 4.0325 & 2589 & 2587 & 64 & 19 & 34.0 & 66.0 & 56 & 39 & $4 \ln 7 \operatorname{Re}$ & - & 35.36 \\
\hline NCDO 2118 & 2555 & 2334 & 66 & 19 & 28.0 & 72.0 & 52 & 16 & $2 \ln 3 \operatorname{Re}$ & 1 & 34.91 \\
\hline KF147 & 2598 & 2537 & 68 & 19 & 19.5 & 80.5 & 93 & 29 & $2 \ln 4 \operatorname{Re}$ & 1 & 34.91 \\
\hline SO & 2489 & 2281 & 64 & 19 & 21.5 & 78.5 & 126 & 45 & $3 \ln 3 \operatorname{Re}$ & - & 35.23 \\
\hline Al06 & 2398 & 2197 & 61 & 19 & 22.9 & 77.1 & 2 & 5 & $1 \ln 1 \operatorname{Re}$ & - & 35.04 \\
\hline CV56 & 2399 & 2301 & 62 & 19 & 23.7 & 76.3 & 51 & 31 & $2 \ln 4 \operatorname{Re}$ & 5 & 35.24 \\
\hline $10-1$ & 2422 & 2233 & 65 & 18 & 23.1 & 76.9 & 8 & 13 & $1 \ln 1 \mathrm{Re}$ & - & 35.10 \\
\hline Average: (lactis) & 2451 & 2364 & 60 & 18 & 21.6 & 78.4 & 31 & 41 & $3 \ln 4 \operatorname{Re}$ & 2.3 & 35.18 \\
\hline \multicolumn{12}{|l|}{ L. lactis subsp. cremoris } \\
\hline 158 & 2250 & 2078 & 60 & 19 & 17.9 & 81.1 & 106 & 150 & $2 \operatorname{Re}$ & 6 & 35.88 \\
\hline UC109 & 2248 & 2081 & 60 & 19 & 20.0 & 80.0 & 98 & 149 & $2 \operatorname{Re}$ & 6 & 35.91 \\
\hline JM1 & 2397 & 2308 & 60 & 19 & 20.5 & 79.5 & 74 & 243 & $1 \ln 6 \operatorname{Re}$ & 7 & 36.01 \\
\hline $\mathrm{JM} 2$ & 2374 & 2316 & 58 & 19 & 19.6 & 80.4 & 68 & 167 & $1 \ln 3 \operatorname{Re}$ & 4 & 35.80 \\
\hline JM3 & 2454 & 2411 & 59 & 19 & 23.7 & 76.3 & 60 & 163 & $2 \ln 3 \operatorname{Re}$ & 5 & 35.87 \\
\hline $\mathrm{JM} 4$ & 2380 & 2293 & 60 & 19 & 20.9 & 79.1 & 88 & 181 & $1 \ln 4 \operatorname{Re}$ & 5 & 35.83 \\
\hline UC509.9 & 2250 & 1947 & 60 & 19 & 18.5 & 81.5 & 182 & 125 & $1 \mathrm{Re}$ & 8 & 35.88 \\
\hline SK11 & 2439 & 2390 & 61 & 20 & 26.2 & 73.8 & 144 & 159 & $2 \ln 3 \operatorname{Re}$ & 5 & 35.86 \\
\hline A76 & 2453 & 2643 & 57 & 19 & 25.8 & 74.2 & 193 & 198 & $2 \ln 7 \operatorname{Re}$ & 4 & 35.88 \\
\hline KW2 & 2427 & 2268 & 61 & 19 & 20.8 & 79.2 & $-{ }^{c}$ & 3 & $1 \ln$ & - & 35.74 \\
\hline MG1363 & 2530 & 2516 & 62 & 7 & 30.8 & 69.2 & 81 & 60 & $2 \ln 4 \operatorname{Re}$ & 1 & 35.75 \\
\hline NZ9000 & 2530 & 2514 & 65 & 19 & 35.3 & 64.7 & 99 & 66 & $2 \ln 5 \operatorname{Re}$ & - & 35.74 \\
\hline Average: (cremoris) & 2394 & 2323 & 60 & 18 & 23.3 & 76.6 & 100 & 138 & $1 \ln 3 \operatorname{Re}$ & 4.25 & 35.84 \\
\hline Average: (lactis \& cremoris) & 2428 & 2344 & 60 & 18 & 22.3 & 77.6 & 59 & 80 & $2 \ln 4 \operatorname{Re}$ & 3.1 & 35.45 \\
\hline
\end{tabular}

${ }^{a}$ In: Complete intact prophage

${ }^{\text {b }}$ Re: Partial/remnant prophage

c Pseudogenes are not specifically indicated

radC [Additional file 1]), resulting in a clear subspecies division in each instance.

To assess the synteny of the lactococcal genomes, whole genome nucleotide alignments were performed and were represented as a dotplot matrix (Additional file 2). L. lactis subsp. lactis 184 was used as a representative strain for the subspecies, first aligned against itself and then against the remaining 17 subsp. lactis genomes. This approach was also employed for the subsp. cremoris genomes using L. lactis subsp. cremoris 158 as the representative strain. Genome synteny was conserved in the lactis subspecies with the exception of the $L$. 


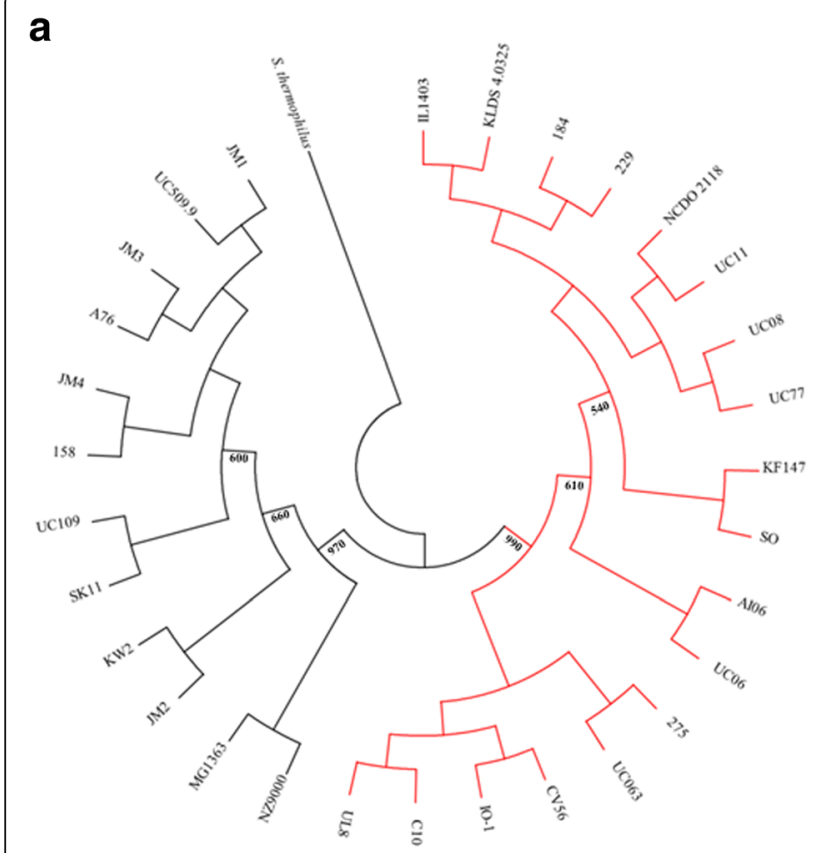

16 s ribosomal $\mathrm{NJ}$ tree

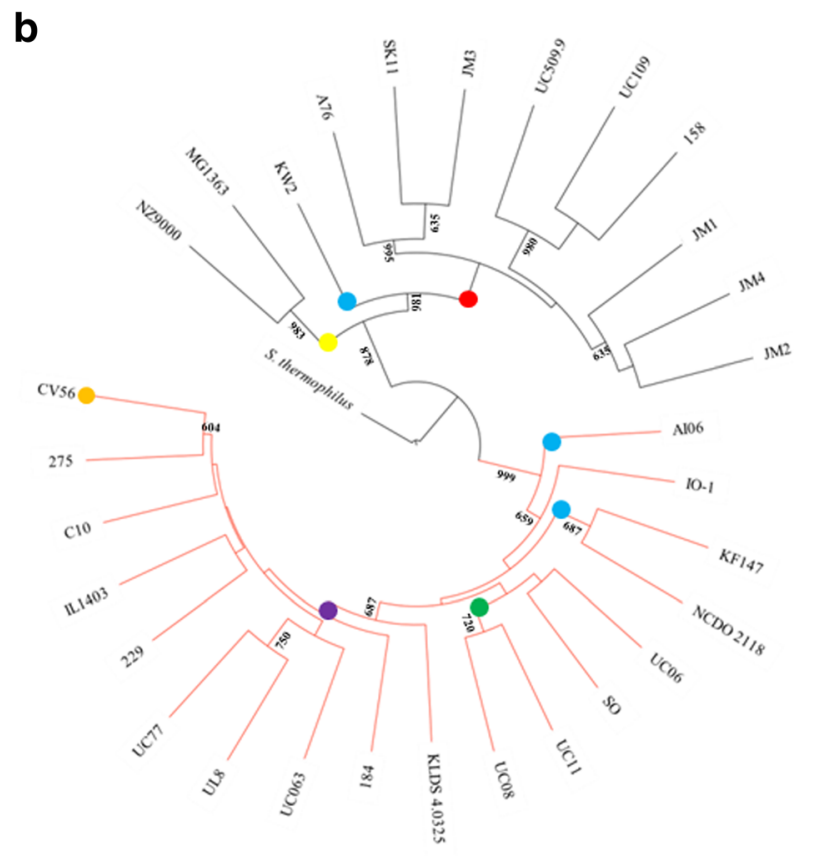

596 concatenated orthologous supertree

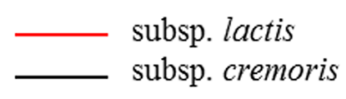

Fig. 1 Phylogenetic analysis of L. lactis taxon. a 165 neighbour-joining ( $\mathrm{NJ}$ ) tree, resulting from the alignment of the $16 \mathrm{~S}$ rRNA-encoding genes of $30 \mathrm{~L}$. lactis isolates, bootstrapped $\times 1000$ replicates, values $>500$ are indicated. The corresponding $16 \mathrm{~S}$ rRNA-specifying sequence of Streptococcus thermophilus LMG 18311 was used as an outgroup. b Multilocus supertree resulting from the alignment of 596 orthologous genes selected from the core genome, bootstrapped $\times 1000$ replicates, values $>500$ are indicated. Ecological niche of representative clades is also indicated

lactis subsp. lactis AI06 chromosome, which revealed a large inversion between coordinates $900 \mathrm{Kbp}$ and $1633 \mathrm{Kbp}$ as previously reported [26].

Genome synteny was significantly less conserved among the subsp. cremoris strains, with in particular L. lactis subsp. cremoris strains A76, JM1, JM2, MG1363 and NZ9000 presenting with multiple chromosomal inversions. In the case of genomes sequenced within the scope of this study (by SMRT sequencing, which generates long individual reads; average $\sim 8 \mathrm{Kbp}$ ), these observed inversions are assumed to be genuine inversions rather than assembly errors. Visual inspection of the SMRT assembly at points intersecting these inversions allowed for the identification of reads spanning across the point of inversion in each case. The increased incidence of chromosomal inversions within these genomes correlates with the observed high number of transposons and other mobile elements (being 198, 243, 167, 71 and 66, respectively) (Table 2). The suspected role of mobile genetic elements in promoting chromosomal inversions was corroborated by sequence inspection of the borders of each of the identified inverted regions, which revealed in all incidences the presence of multiple transposable elements or integrated prophage(s) (data not shown).

\section{Pan/core-genome analysis}

To evaluate current sequencing efforts of the L. lactis taxon and to determine if additional genome sequencing is necessary to provide a complete overview of the chromosomal diversity of this taxon, pan-genome analysis was applied using the PGAP v1.0 pipeline [27]. The analysis was applied to the chromosomes of $L$. lactis only and excluded plasmid sequences as the main aim of this paper is to report on chromosomal diversity rather than mobile genetic elements. The resulting graph (Fig. 2) reveals an asymptotic curve increasing at an 


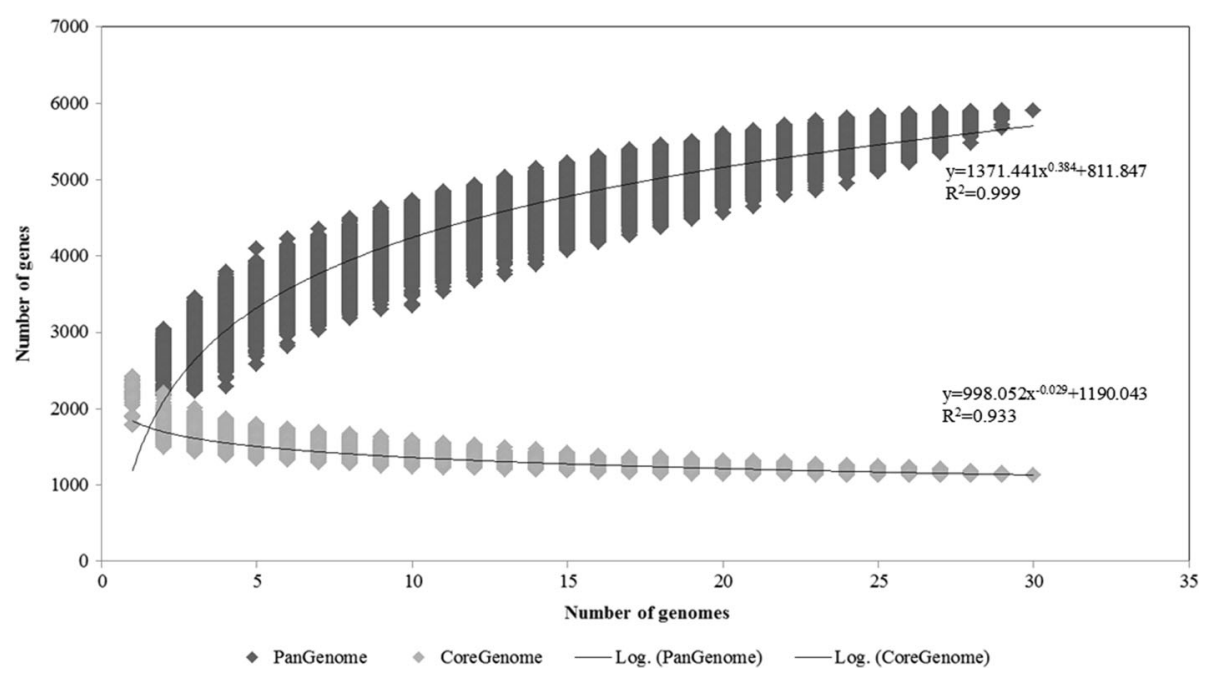

Fig. 2 Pan-genome and core-genome of L. lactis. Represents accumulated number of new genes in the L. lactis pan-genome plotted against the number of genomes added and the accumulated number of genes attributed to the core-genome plotted against the number of added genomes. The deduced mathematical functions are also indicated

average rate of 209.44 genes for the first 11 chromosomes analysed. Beyond this point, the rate of pangenome increase slows to an average of 86 genes per genome added for the remaining 19 strains in the analysis resulting in a pan-genome constituted by 5906 genes. The majority of new genes added at this point in the analysis are short hypothetical coding sequences (CDSs) which do not contribute greatly to our current understanding of the genetic diversity of these strains. The deduced mathematical function is also displayed (Fig. 2) and the exponential value $(<0.5)$ indicates that the pan-genome is in a closed state [20].

Using the approach outlined above, it was also possible to deduce the core genome size (Fig. 2) of 1129 genes. Conversely, when the subspecies are separated and the analysis repeated, the core genome size increases to 1406 genes for subsp. cremoris and 1413 genes for subsp. lactis (data not shown), thus indicating that 277 and 284 additional genes are conserved in all subp. cremoris and subp. lactis strains, respectively, although not exclusively confined to either species. In the course of this analysis the previously published genomes which were incorporated were not re-annotated as comparison of the genomes sequenced in this study with those previously published indicated that the gene calling and identified ORFs within each of the genomes were largely identical and did not represent significant enough differences to bias the analysis. On completion of the core genome, the variable regions were examined by DNA based alignments utilising BLASTN to ensure that ORFs were absent as a result of missing DNA as opposed to differences in gene calling.
Overall, both analyses show that $L$. lactis contains an essentially closed pan-genome (excluding the plasmid complement) and that there are a sufficient number of strains included in this study to describe the complete genetic repertoire of the taxon.

\section{Comparative analysis of orthologous genes}

To assess the level of (functional) diversity within the lactococcal core and dispensable genomes, comparative analysis was performed via all-against-all, bi-directional BLASTP alignment, and clustering implemented in the MCL pipeline [28, 29]. The core genome of 1129 genes, as defined above, was found to comprise 904 orthologous (single copy) gene families and 225 paralogous (multi-copy) gene families. Gene families unique to each chromosome were also calculated (Fig. 3a) and totalled 757 unique gene families across the 30 assessed $L$. lactis isolates. BLASTP analysis showed that $65 \%$ of these unique or dispensable gene families encode proteins of unknown function, while a further $16 \%$ encode phage proteins acquired through the integration of a particular prophage-like element. The remaining unique gene families were predominantly found to be representing plasmid integration events encoding proteins involved in mobilisation and conjugation, integrated mobile elements such as transposases and IS elements, or systems that provide specific benefit to the bacterium such as restriction-modification systems, bacteriocin production, and sugar transport and metabolism (Additional file 3).

Cluster of Orthologous Group (COG) analysis was employed to further classify both the core and dispensable genome of L. lactis. The 30 lactococcal chromosomes analyzed in this study were classified using COG 
a

\section{Lactis subsp. Lactis 184}

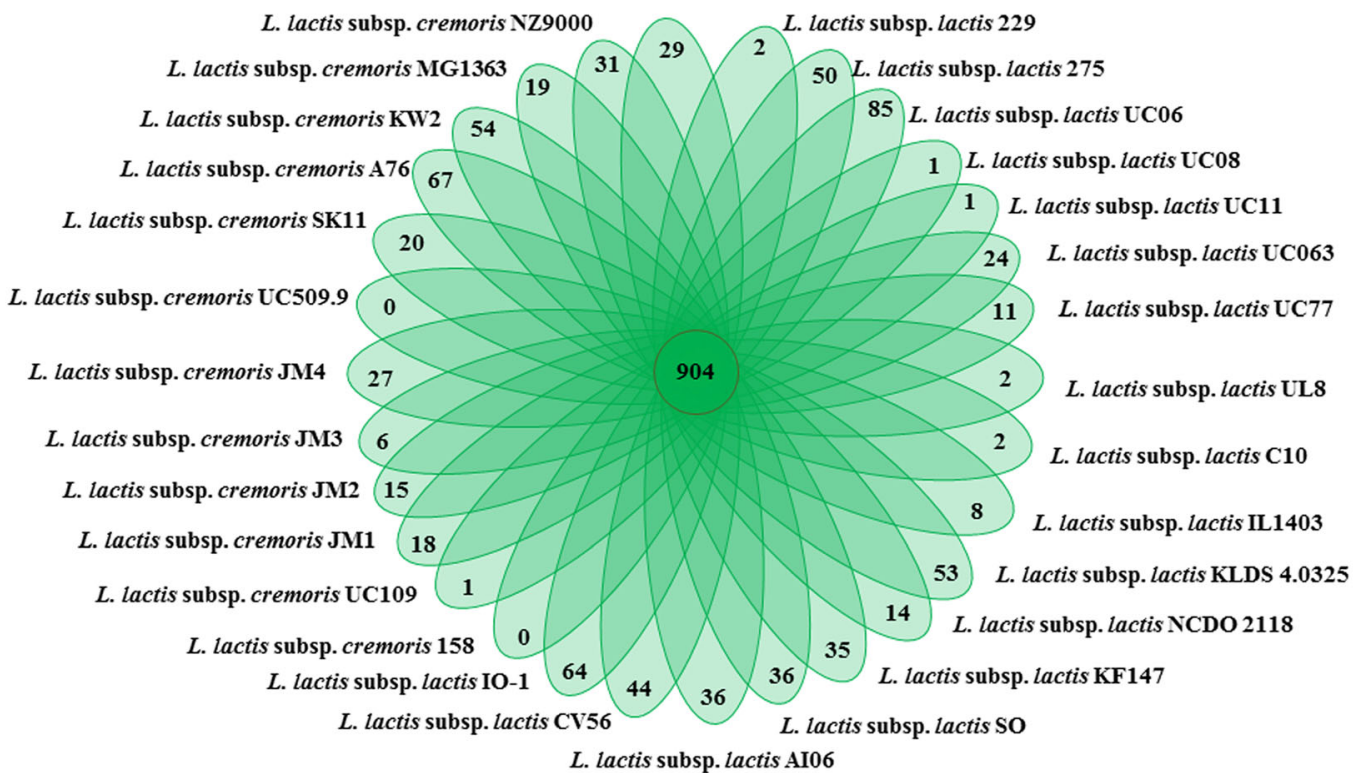

b

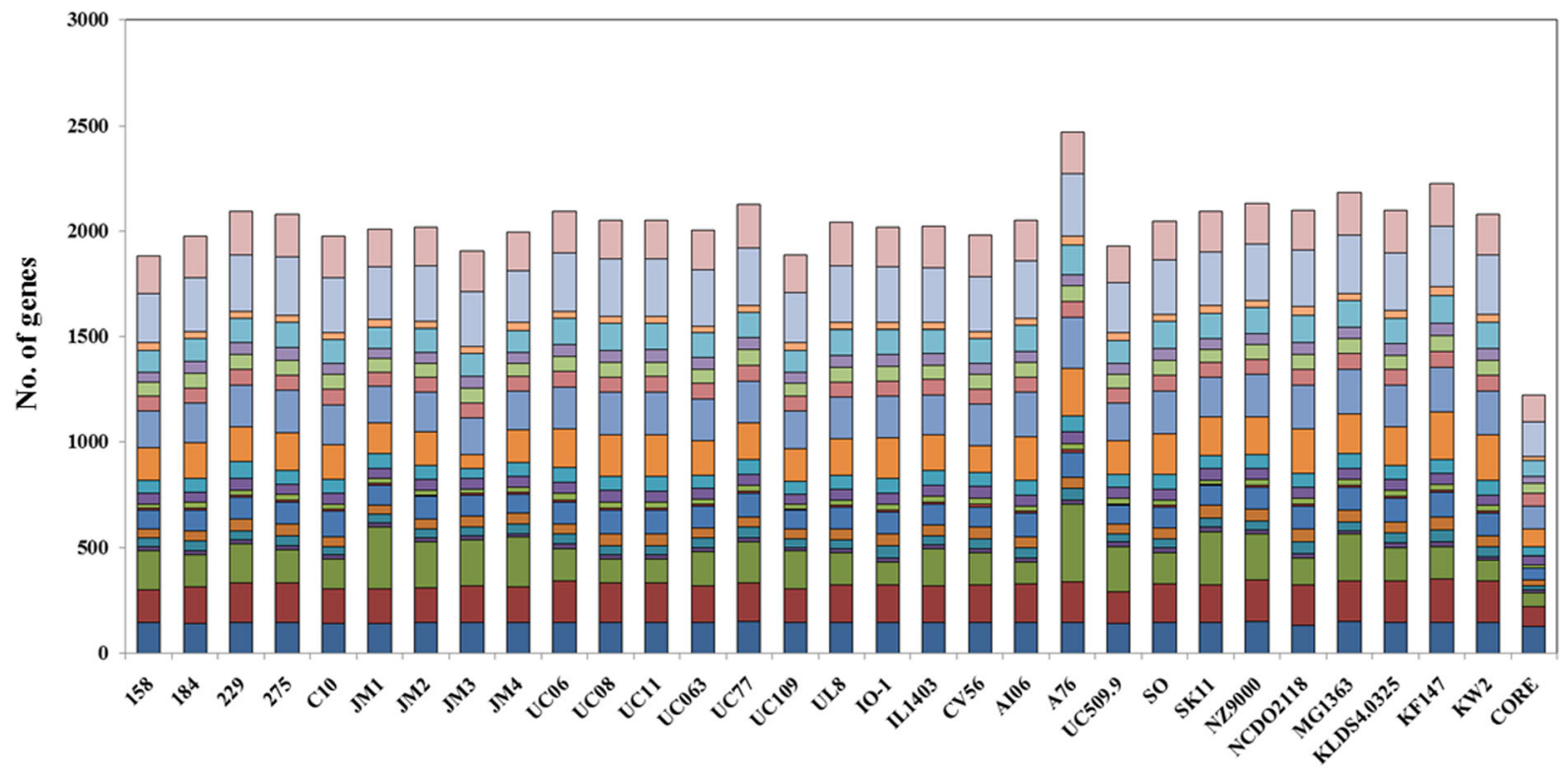

घTranslation, ribosomal structure and biogenesis $\square$ Replication, recombination and repair $\square$ Defense mechanisms

口Cell wall/membrane/envelope biogen esis

$\square$ Intracellular trafficking, secretion, and vesicular transport

口Energy production and conversion

$\square$ Amino acid transport and metabolism

$\square$ Coenzyme transport and metabolism

$\square$ In organic ion transport and metabolism

$\square$ General function prediction only
aTranscription

aCell cycle control, cell division, chromosome partitioning $\square$ Signal transduction mechanisms

$\square$ Cell motility

$\square$ Posttranslational modification, protein turnover, chaperones

$\square$ Carbohydrate transport and metabolism

$\square$ Nucleotide transport and metabolism

$\square$ Lipid transport and metabolism

$\square$ Secondary metabolites biosyn thesis, transport and catabolism

口Function unknown

Fig. 3 (See legend on next page.) 
(See figure on previous page.)

Fig. 3 Comparative genomics of orthologous protein groups. a Venn diagram displaying core gene families obtained by MCL clustering, and unique genes of $30 \mathrm{~L}$. lactis isolates. b Cluster of Orthologous Groups (COGs) classification of L. lactis. Histograms represent COG predictions for the complete genomes of: L. lactis 158, L. lactis 184, L. lactis 229, L. lactis 275, L. lactis C10, L. lactis JM1, L. lactis JM2, L. lactis JM3, L. lactis JM4, L. lactis KF147, L. lactis KLDS 4.0325, L. lactis KW2, L. lactis MG1363, L. lactis NCDO 2118, L. lactis NZ9000, L. lactis SK11, L. lactis SO, L. lactis UC06, L. lactis UC08, L. lactis UC11, L. lactis UC063, L. lactis UC77, L. lactis UC109, L. lactis UC509.9, L. lactis A76, L. lactis Al06, L. lactis CV56, L. lactis IL1403, L. lactis $1 \mathrm{O}-1$ and the L. lactis core genome

analysis. The core genome was predominantly composed of genes involved in housekeeping functions, fundamental to growth and survival, while $24 \%$ of the genes contained in the core genome were assigned to COG groups $[R]$ and $[S]$ representing genes, for which a general function was predicted or which are of unknown function (Fig. 3b).

COG classification was also performed on the nonoverlapping parts of the core genomes of subsp. cremoris and subsp. lactis, thus focusing on conserved features that differentiate the two subspecies (Table 3). This analysis identified CDSs predicted to be involved in metabolism, particularly transport and metabolism of carbohydrates (Table 3) as the major discerning factor between the two subspecies. Further examination of these subspeciesspecific, conserved gene set demonstrates that subsp. lactis conserved more unique genes than subsp. cremoris, particularly related to metabolism, 124 compared to 68 , respectively. The reduced number of CDSs encoding products related to metabolism in subsp. cremoris strains is noteworthy as it is in agreement with the generally observed reduced metabolic capabilities of subsp. cremoris strains, and highlights the reductive pressure and genome decay imposed on these strains predominantly isolated from the dairy niche.

\section{Metabolism and niche adaptation}

To explore the divide between the subspecies in terms of their metabolic capabilities and to highlight particular niche adaptations within the strains, MCL analysis was employed to compare the COG groupings based on function i.e. [G] carbohydrate transport and metabolism, [E] amino acid transport and metabolism and [I] lipid transport and metabolism. These COG groups are

Table 3 COG classifications of the core genomes of L. lactis, L. lactis subsp. lactis and L. lactis subsp. cremoris

\begin{tabular}{|c|c|c|c|}
\hline \multirow[t]{2}{*}{ COG classification } & \multirow[b]{2}{*}{ L. lactis core genome } & \multicolumn{2}{|c|}{ Unique core genomes } \\
\hline & & L. lactis subsp. lactis & L. lactis subsp. cremoris \\
\hline Translation, ribosomal structure and biogenesis & $10 \%$ & $<1 \%$ & $5 \%$ \\
\hline Transcription & $8 \%$ & $11 \%$ & $9 \%$ \\
\hline Replication, recombination and repair & $6 \%$ & $3 \%$ & $6 \%$ \\
\hline Cell cycle control, cell division, chromosome partitioning & $1 \%$ & $<1 \%$ & $<1 \%$ \\
\hline Defence mechanisms & $1 \%$ & $4 \%$ & $3 \%$ \\
\hline Signal transduction mechanisms & $2 \%$ & $2 \%$ & $2 \%$ \\
\hline Cell wall/membrane/envelope biogenesis & $5 \%$ & $4 \%$ & $4 \%$ \\
\hline Cell motility & $<1 \%$ & $1 \%$ & $1 \%$ \\
\hline Intracellular trafficking, secretion, and vesicular transport & $1 \%$ & $<1 \%$ & $2 \%$ \\
\hline Posttranslational modification, protein turnover, chaperones & $4 \%$ & $1 \%$ & $<1 \%$ \\
\hline Energy production and conversion & $4 \%$ & $4 \%$ & $3 \%$ \\
\hline Carbohydrate transport and metabolism & $7 \%$ & $14 \%$ & $10 \%$ \\
\hline Amino acid transport and metabolism & $9 \%$ & $15 \%$ & $5 \%$ \\
\hline Nucleotide transport and metabolism & $5 \%$ & $1 \%$ & $1 \%$ \\
\hline Coenzyme transport and metabolism & $4 \%$ & $2 \%$ & $2 \%$ \\
\hline Lipid transport and metabolism & $3 \%$ & $3 \%$ & $3 \%$ \\
\hline Inorganic ion transport and metabolism & $6 \%$ & $4 \%$ & $3 \%$ \\
\hline Secondary metabolites biosynthesis, transport and catabolism & $2 \%$ & $1 \%$ & $2 \%$ \\
\hline General function prediction only & $14 \%$ & $6 \%$ & $10 \%$ \\
\hline Function unknown & $10 \%$ & $23 \%$ & $27 \%$ \\
\hline
\end{tabular}

Bold rows indicate those were a significant difference exists within the unique core genomes 
fundamental to niche adaptation as they provide an overview of a strain's ability to metabolise different energy sources. They may also include key technological traits sought in strains utilised in the dairy niche where the majority of sequenced strains have been isolated. Until now, the focus of this study has been on chromosome specific traits, however, in order to gain an overall view of the total metabolic capabilities of a strain it is necessary to also consider extra-chromosomal encoded traits. Therefore, both chromosomally- and plasmidencoded features were considered for the remainder of the comparative analysis.

MCL analysis of COG [G] functions (genes involved in carbohydrate transport and metabolism) across all 30 isolates resulted in a gene presence/absence matrix displaying five groupings specific to niche environments (Fig. 4). The majority of analysed lactococcal genome sequences are derived from isolates from the dairy niche, where the most important adaptation is the ability to ferment lactose, facilitated by the products of the plasmid-borne lac operon, which consists of the lacABCDEFGX genes [8, 9]. The complete lac operon was identified in all subsp. cremoris strains isolated from the dairy niche except for the plasmid-free strains MG1363 and its derivative NZ9000. However, MG1363 has previously been shown to metabolise lactose due to the activity of a cellobiosespecific phosphotransferase system (PTS), which can act as an alternative lactose utilisation pathway under glucose starvation conditions [30]. The complete lac operon was also identified in six of the 11 subsp. lactis dairy isolates, yet not in the remaining five (strains 184, C10, UL8 and IL1403), of which L. lactis IL1403 is known to be a plasmid-cured strain [31]. When strains C10 and UL8 were inoculated in 10\% RSM (reconstituted skimmed milk), they displayed no signs of growth or acidification, which is consistent with the observed absence of the lac operon. However, in the case of strain 184, growth on lactose is still observed, which can be explained by the presence of the cellobiose-specific phosphotransferase system (PTS), similar to the situation in MG1363 [30]. Interestingly, while all dairy-derived cremoris strains form a single cluster based on genes involved in carbohydrate metabolism with the exception of the laboratory strains MG1363 and NZ9000 (Group 4), all dairy-derived lactis strains (Group 1) with the exception of strains $\mathrm{SO}$ and UC06 (Group 2) form a single separate cluster to their cremoris counterparts based on carbohydrate utilisation. The only human isolate of L. lactis included in our analysis is also contained within Group 1. Differentiating factors, such as the clusters responsible for maltose utilisation found in all lactis strains and non-dairy cremoris strains, and for xylose metabolism as observed in all cremoris strains (with the exception of JM1), yet not present in lactis strains, contribute to this division (Fig. 4b). A major bifurcation in the HCL matrix between the two constituent subspecies was also observed, mirroring that of the supertree (Fig. 1b). Furthermore, the observed hierarchical groupings for the cremoris subspecies (Groups 4-5) closely relate to those observed in the supertree. Conversely, the observed groupings of the lactis subspecies (Groups 1-3) differ from those observed in the supertree as their increased metabolic abilities in terms of carbohydrate utilisation are not shown in the supertree which is built on conserved orthologous proteins. The clustering in the matrix is based on the absence/presence of proteins and as such none of these differences are included in the supertree.

The genomes of L. lactis UC08 and UC11 represent the only two complete lactococcal genome sequences isolated from fermented meat. In this analysis, these strains clustered closely with those derived from non-dairy sources, particularly plant-derived strains based on carbohydrate metabolism (Group 3). Genes encoding functions involved in pentose and glucuronate interconversions are found exclusively in strains isolated from the plant and meat niches, and thus are not present in any other lactococcal strain. These sugars are generally not found in milk where the primary sugar source is lactose with only trace amounts of monosaccharides and oligosaccharides. The majority of strains examined in this study are dairy isolates and so it is plausible that these functions have been lost through reductive evolution in strains adapted to the rich growth media provided by the dairy environment.

Supplementing COG analysis with information obtained from KEGG (Kyoto encyclopaedia of genes and genomes) analysis, a full assessment of all major metabolic pathways present in L. lactis was undertaken (Additional file 4). In this case complete pathways for D-galacturonate degradation (KEGG accession: M00631) and beta-oxidation, acyl-CoA synthesis (KEGG accession: M00086) were exclusively identified in the plant-derived strains NCDO2118 and KF147.

It has previously been demonstrated that both $L$. lactis subsp. cremoris and subsp. lactis are capable of folate biosynthesis [32]. Interestingly, KEGG analysis showed all analysed subsp. lactis strains to lack a complete pathway for tetrahydrofolate biosynthesis (KEGG accession: M00126) which was found to be complete in all subsp. cremoris strains. In cremoris strains the pathway was found to consist of nine genes responsible for conversions from purine metabolism to folate, whereas in subsp. lactis strains, the phoA gene that encodes an alkaline phosphatase (E3.1.3.1), responsible for the conversion of 7,8dihydroneopterin 3-triphosphate to dihyroneopterin, appears to be absent. This indicates that this step in tetrahydrofolate biosynthesis in subsp. lactis is performed by an alternative and as yet unidentified enzyme (in comparison to their cremoris counter-parts). 


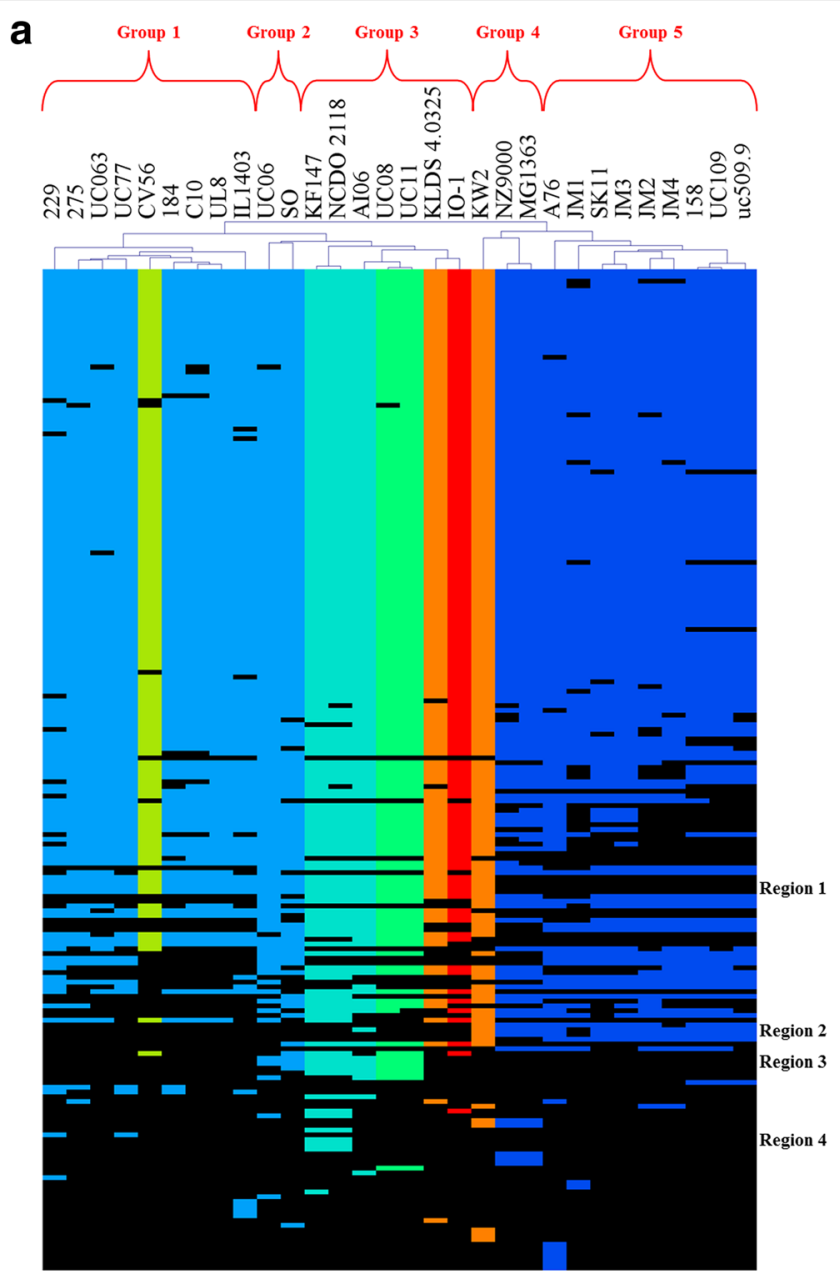

b Region 1

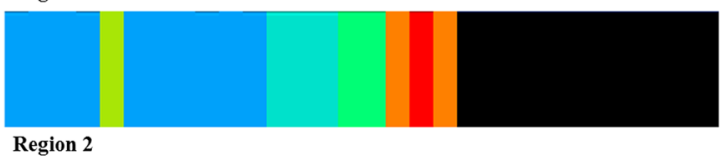

lacto-N-biosidase

malE; maltose/maltodextrin transport system substrate-binding protein

Maltose sugar hydrolase

fructose-6-phosphate phosphoketolase

Region 2

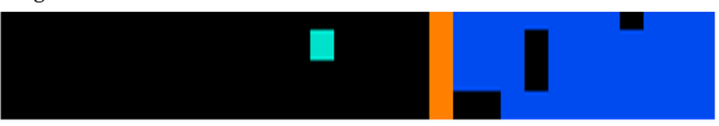

xylose abc transporter permease

xylan 1,4-beta-xylosidasen

Endoglucanase

Arabinose efflux permease

\section{Region 3}

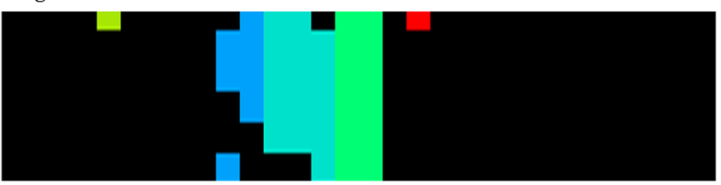

sucrose-6-phosphate hydrolase

L-Ribulokinase

L-Arabinose isomerase

L-Ribulose-5-phosphate 4-epimerase

Polysaccharide biosynthesis protein

hypothetical protein

Region 4
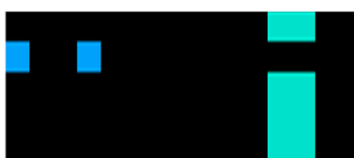

Endoglucanase

Xylulokinase

Tagaturonate reductase

Altronate dehydratase

Altronate dehydratase
Altronate oxidoreductase
$\square$ Dairy cremoris
$\square$ Dairy lactis
$\square$ Plant
$\square$ Fermented food
$\square$ Meat
$\square$ Human Isolate
$\square$ Sink Drain
$\square$ Ferment

Fig. 4 (See legend on next page.) 
(See figure on previous page.)

Fig. 4 Carbohydrate utilisation and niche adaptation. a Hierarchical clustering analysis representing the presence/absence of gene families from COG group [G], carbohydrate transport and metabolism. Gene clusters are indicated based on the hierarchical tree, top. Colour indications refer to the particular niche from which the L. lactis strain had been isolated. $\mathbf{b}$ Enlarged views of variable regions 1-4 from the HCL matrix, involved in maltose and xylose transport and metabolism, and pentose and glucoronate interconversions

\section{Amino acid transport and metabolism}

Proteolysis (of casein) performed by L. lactis has been widely studied as it is considered to be an important technological trait in dairy lactococci due to its contribution to flavour in fermented dairy products such as cheese, as outlined by a number of reviews that detail this process [33-35]. The main categories of peptidases contributing to proteolysis in L. lactis are aminopeptidases, endopeptidases, di/tri-peptidases, proline peptidases, endopeptidases and carboxypeptidases. The majority of described peptidase-encoding genes represent monocistronic elements (e.g. pepC, pepN and prt $P$ ), while others are transcribed with genes apparently unrelated to proteolysis [36]. To assess the level of peptidase activity within $L$. lactis, both functional and genomic analyses were undertaken. Quantitative assays utilising fluorescently labelled substrates (see Materials and Methods section) were used to determine the activity levels of PepN/ C, PepA, PepX, proline imino peptidase, carboxypeptidase and endopeptidase produced by each strain (Fig. 5a \& b). The dominant peptidase activities expressed by each strain were those represented by the proline peptidase PepX and the aminopeptidases PepA and PepN/C. Interestingly, all of these peptidases are present in single-copy in each of the chromosomes, though the measured activity levels do vary considerably between strains. To ascertain a broader perspective on peptidase or amino acid digestion, an MCL analysis of COG group [E] amino acid transport and metabolism was performed (Fig. 5c). Clustering based on the presence or absence of genes involved in amino acid transport and metabolism resulted in two major groupings: the first composed of subsp. lactis strains and the second composed of cremoris strains indicating that the proteolytic system of these bacteria is distinct between and relatively well conserved within each subspecies.

Another important factor in assessing the proteolytic system of Lactococcus is the effect of amino acid transferases, which convert free amino acids to $\alpha$-ketoacids. This is of particular importance when considering strains which may be used within the fermented food industry for the production of cheeses where aminotransferases contribute to flavour and aroma development [37]. As a high proportion of the current lactococcal dataset is currently composed of strains from the dairy niche, we assayed the strains for amino acid transferase activity against phenylalanine (aromatic amino acid) and methionine (sulphur amino acid), which are both common in milk and important in terms of cheese production. All strains demonstrated aminotransferase activity against phenylalanine (Fig. 6a) and a considerably higher level of activity against methionine (Fig. 6b). With the exception of L. lactis subsp. cremoris JM4, strains of the cremoris subspecies were shown to display significantly higher levels of aminotransferase activity compared to their lactis counterparts.

Markov clustering of aminotransferases in L. lactis strains was carried out and resulted in clades, which closely resemble the level of activity expressed by the constituent strains (Fig. 6c). Interestingly, strains SK11, JM2, and KW2, which exhibited the highest level of activity for both phenylalanine and methionine, did not encode the highest number of aminotransferases, and none of these strains specify a histidinol-phosphate/aromatic aminotransferase. Overall, both the peptidase and aminotransferase analyses indicated a very divergent proteolytic system between the two subspecies.

\section{Lipid transport and metabolism}

MCL analysis combined with hierarchical clustering of COG group [I] (lipid transport and metabolism) revealed two main groups based on predicted lipolytic activity; the first was composed of both subsp. lactis and cremoris strains from mixed sources, while the second was composed exclusively of dairy cremoris strains, namely strains JM1, JM2, JM3, JM4, 158, UC109 and UC509.9. These strains encode a well-conserved lipolytic system, while lipolytic assays utilizing $p$-nitrophenyl-butyrate for the detection of short chain esterase activity revealed a trend showing higher expression of esterase activity by these strains compared to their subsp. lactis and nondairy subsp. cremoris counterparts (Fig. 7).

\section{Plasmid integration}

Bacterial adaptation relies heavily on the metabolic capabilities of the cell. In the case of L. lactis the most studied adaptations are those related to the dairy environment where reductive evolution or genome decay is observed among strains, a phenomenon which is believed to be due to repeated passaging in the nutrient-rich growth medium, milk $[6,7,38]$. As well as the loss of redundant metabolic functions to reduce energy- and resource-demanding systems in such a niche, the acquisition of new genetic information encoding traits that are advantageous to the host (in the particular niche) is often necessary. In $L$. lactis, the most notable example is adaptation to the dairy environment via the plasmid-borne lac operon, which allows for lactose utilisation as the primary sugar source, 


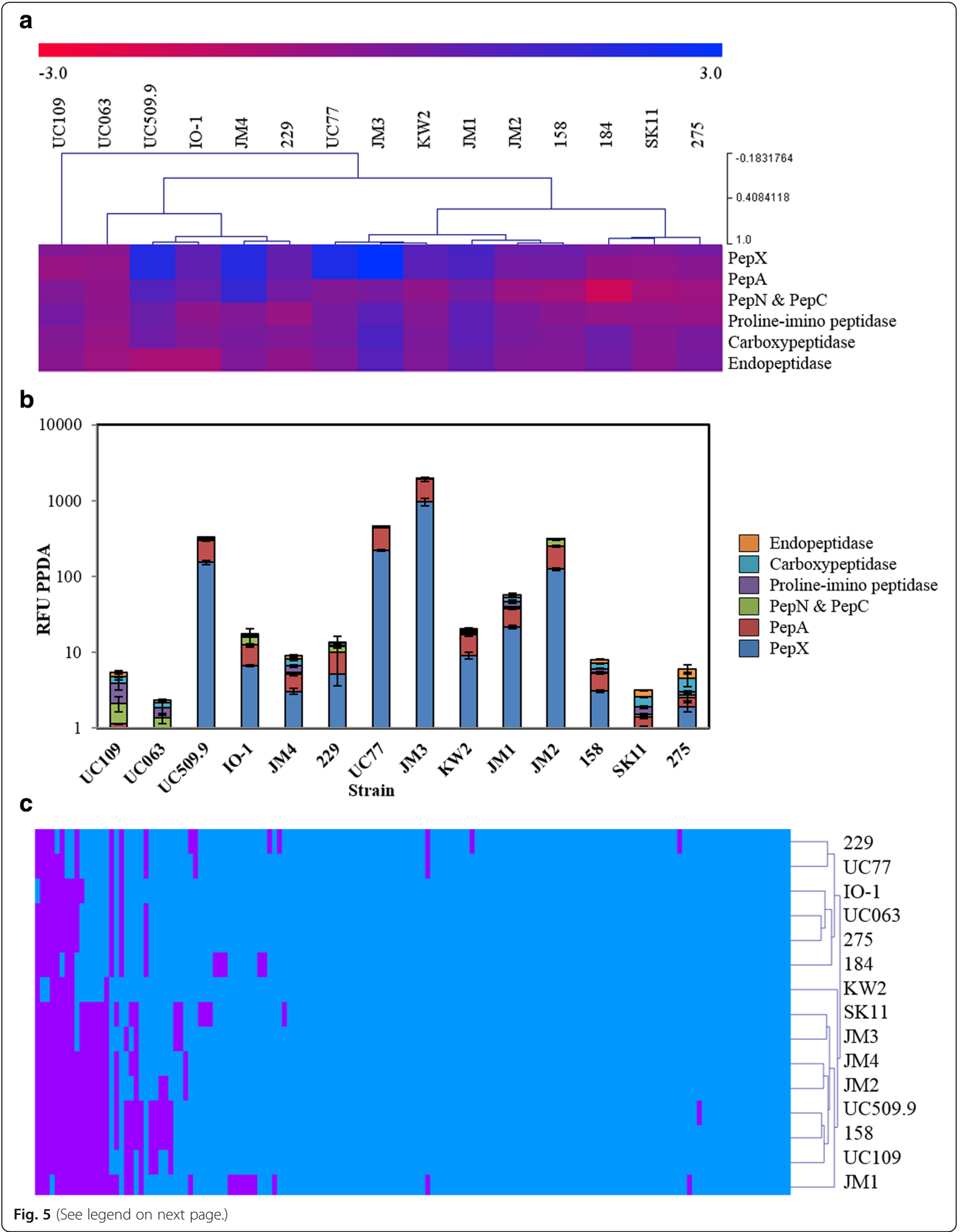


(See figure on previous page.)

Fig. 5 Peptide metabolism in L. lactis. a Level of PepX, PepA, PepN/C, Proline imino peptidase, endopeptidase and carboxypeptidase activity, expressed by L. lactis in log(RFU PPDA) where (1 RFU = the amount of $\mu \mathrm{M}$ of AMC released $\mathrm{min}^{-1}$ by $1 \mathrm{mg}$ of protein). Strains are clustered based on activity red-blue indicating increased activity. $\mathbf{b}$ Total peptidase activity expressed by lactococcal strains for PepX, PepA, proline imino peptidase, endopeptidase, carboxy-peptidase and PepN/C in RFU PPDA (1 RFU = the amount of $\mu \mathrm{M}$ of AMC released $\mathrm{min}^{-1}$ by 1 mg of protein. $\mathbf{c}$ Hierarchical clustering analysis representing the presence/absence of gene families from COG group [E] amino acid transport and metabolism

and the prtP-encoded protease and the opp operon responsible for amino acid/nitrogen acquisition from the milk protein casein. However, in some instances integration of such genetic features into the host's chromosome may take place.

In silico based analysis of the chromosomes of 30 lactococcal isolates resulted in the identification of (1-6) integrated regions with significant $(>90 \%)$ nucleotide identity to previously sequenced lactococcal plasmids (Additional file 5). The most notable of these putative integrations was the presence of the opp operon, originally identified as a plasmid-encoded trait in dairy $L$. lactis [39], conserved in the chromosomes of 24 out of 30 strains. The region shares (>90\%) nucleotide identity with lactococcal plasmids pIL4, pQA549, pCIS8, pSK11L/SK11 plasmid 4, pVF50 and pGdh442. L. lactis MG1363 and its derivative L. lactis NZ9000 also harbour the associated prtP gene in the same integration site; however, it is integrated at approximately 680-690 Kbp on the chromosome. In one instance, for L. lactis SO, the associated lac operon, which controls lactose utilisation in the dairy niche, was detected on the chromosome, $20 \mathrm{Kbp}$ downstream of the integrated opp operon and sharing significant homology with plasmids pCV56B, pSK08, pKF147A and pNCDO2118.

A number of other features that are typically observed among the plasmid complements of lactococci were identified in the chromosomes of the assessed strains including restriction-modification systems, conjugal transfer and mobilisation or mob genes, a partial lactococcin gene cluster (four instances) and a partial exopolysaccharide biosynthesis gene cluster (nine instances). The frequency of occurrence of these regions suggests that the total genetic complement of L. lactis is in a state of flux.

\section{Discussion}

Recent advances in NGS technologies have made it easier to sequence a far greater number of high-quality bacterial genomes than ever before. In this study SMRT sequencing was applied for the complete sequencing of sixteen lactococcal genomes, more than doubling the existing number of publicly available, fully sequenced lactococcal genomes. The chromosomal features of $L$. lactis were assessed with particular emphasis on discerning the subspecies classification and niche adaptation of L. lactis.

Our analysis clearly identified a phylogenetic division between subspecies lactis and cremoris. This subspecies division was corroborated by hierarchical clustering based on both carbohydrate and amino acid metabolism, which indicates two main subgroups that correspond to each subspecies. Furthermore, for a number of conserved genes investigated in this study, a unique allelic type was observed for strains belonging to subsp. lactis and a separate allelic variant observed for strains belonging to subsp. cremoris. These observations support those made by Cavanagh and colleagues, who recently proposed a re-evaluation of the taxonomic group separating L. lactis into two distinct species L. lactis and L. cremoris based on ANI (average nucleotide identity) and TETRA (tetranucleotide frequency correlation coefficients) [16].

The percentage of pseudogenes within the sixteen lactococcal genomes sequenced in this study varies from 0.5 to $5.1 \%$, when calculated as a percentage of the total number of coding sequences and is strain specific. Overall for the sixteen genomes sequenced in this study, this corresponds to an average pseudogene occurrence per strain of $1.76 \%$, a percentage that is in line with the majority of prokaryotes [40]. The genomes of L. lactis subsp. cremoris were found to contain a higher number of pseudogenes in comparison to their L. lactis subsp. lactis counterparts, on average 100 per strain compared to 31 per strain, respectively. The vast majority of these strains are isolated from the dairy niche where genome decay and redundancy is widely reported [6, 38, 41], and believed to be due to continuous growth in milk. These genomes were also shown to contain a high number of prophages and transposable elements in agreement with Chopin and colleagues [5], and assumed to be the result of continued industrial pressures. Such prophages represent a risk factor, which warrants thorough assessment before introducing such strains into industrial fermentations. Conversely, the genomes of lactococcal strains isolated from both meat or plant environments displayed greater genetic variation and encode a greater number of metabolic pathways for the utilisation of a broader range of substrates compared to dairy-associated lactococci. The isolation of strains from these non-dairy sources may provide novel cultures for food fermentations and deliver desirable capabilities in terms of flavour and industrial robustness as dairy starter cultures.

COG analysis of L. lactis subsp. cremoris and lactis showed a higher proportion of genes involved in information processing and storage in cremoris strains and a 


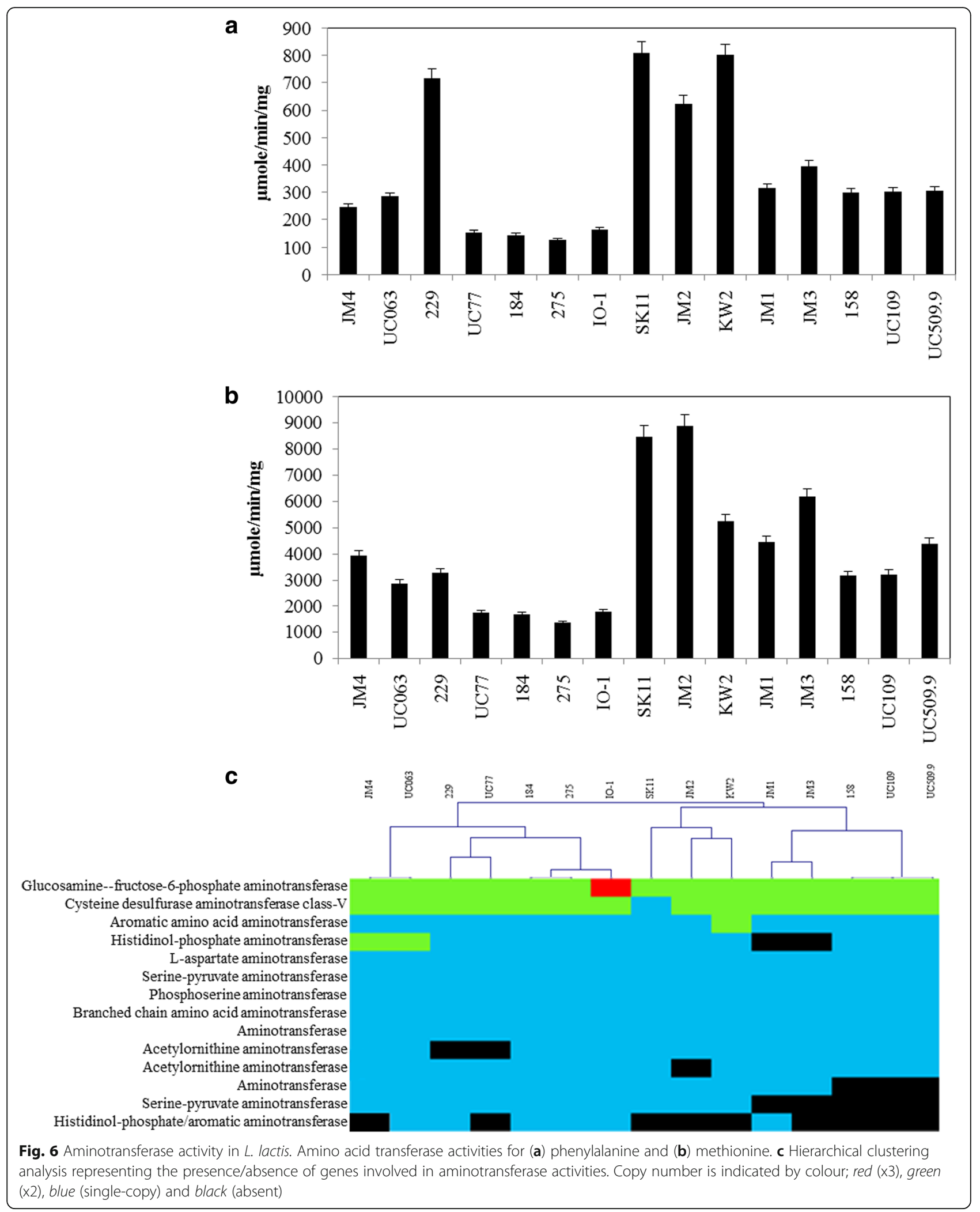




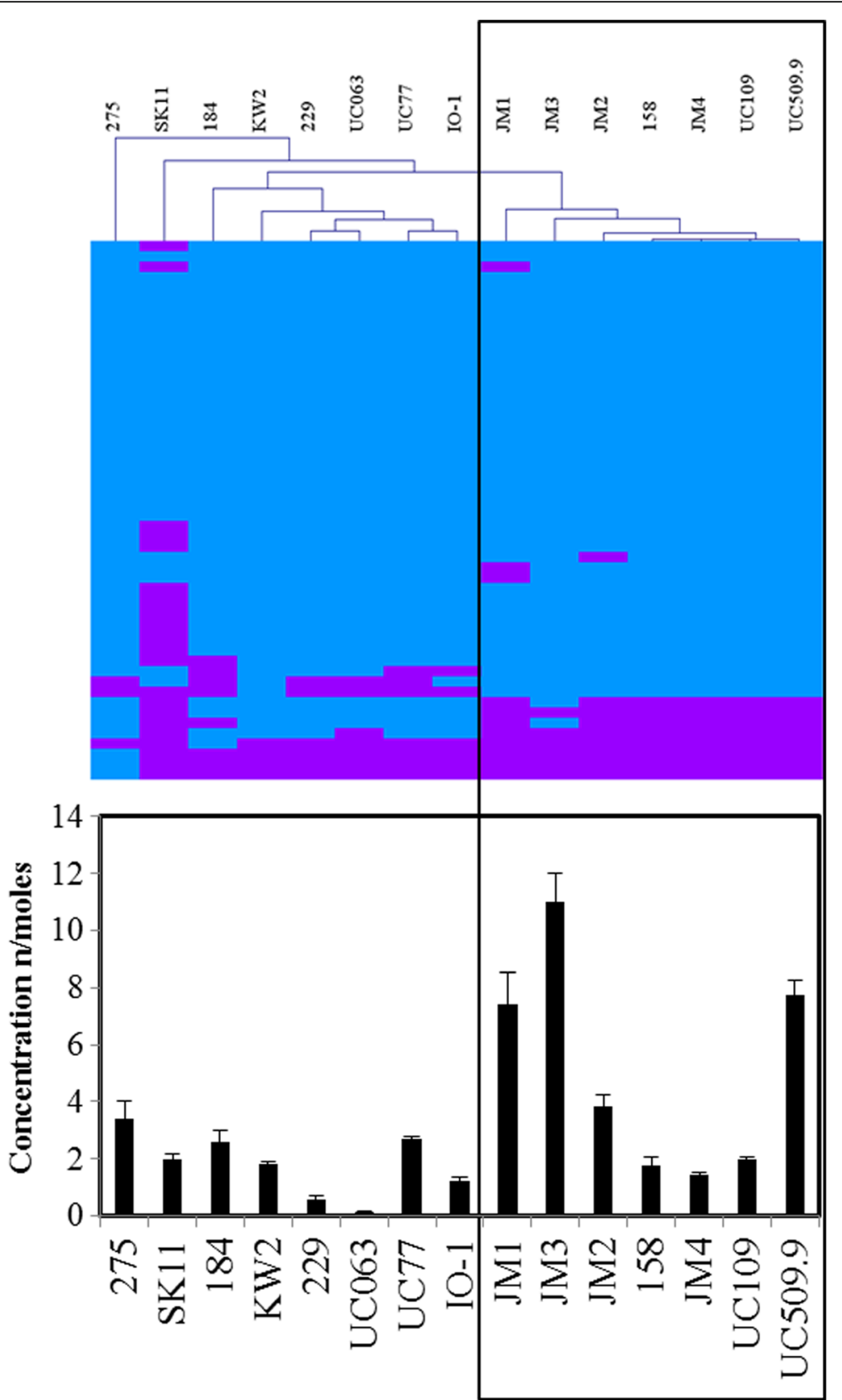

Fig. 7 Lipid metabolism in L. lactis. Hierarchical clustering analysis representing the presence/absence of gene families from COG group [1] lipid transport and metabolism with associated histogram indicating level of short chain esterase activity of each constituent strain

higher proportion involved in metabolism in lactis strains, in the specific portions of the core genome the two subspecies do not share. This is in agreement with the generally observed reduced metabolic capabilities of subsp. cremoris strains, and highlights the reductive pressure through genome decay imposed on these (mostly) dairy-derived strains. This may also be conducive to the observed faster growth rate of lactis strains compared to their cremoris counterparts under milk fermentation conditions (Additional file 6). COG analysis was also utilised as a mechanism for functional genomic analysis in examining both peptide and lipid metabolism. It was determined that although strains can be genotypically clustered based on their subspecies and common niche, in agreement with a previous study [36], many of the peptidases for which functional assays are available exist in single copy in the majority of lactococcal genomes. Therefore, it may not always be possible to make the genotype-phenotype link without the involvement of transcriptome and/or metabolome-based studies 
to support the data. Interestingly, both peptidase and aminotransferase analyses indicated a very divergent proteolytic system between the two subspecies and relatively well conserved within each subspecies.

Niche adaptation also relies heavily on the acquisition of new metabolic capabilities as well as the loss of unnecessary functions. The introduction of niche-specific adaptations via plasmid acquisition, such as lactose and citrate metabolism has been extensively studied in L. lactis in view of their role in dairy niche adaptation [4, 8-10, 42], however, chromosomal adaptations are largely underrepresented by comparison. Interestingly, the division between plasmid- and chromosome-based traits is becoming less clear as multiple integration events within the lactococcal chromosome suggests a more fluid genome than previously thought [4].

\section{Conclusions}

In conclusion, the sequencing of 16 novel lactococcal isolates has doubled the number of complete finished quality lactococcal genomes available and allowed for large-scale comparative analysis of the complete metabolic systems of the taxon. Analysis of the two lactococcal subspecies revealed unique allelic subtypes for many of the conserved genes within each subspecies raising the question of their taxonomic placement and if the two subspecies should be redefined as separate species. Niche adaptation appears to play a significant part in governing the genetic content of each constituent strain, while genome decay and redundancy in the dairy niche is also widely observed. The deduced pan-genome of $L$. lactis is apparently closed, indicating that the representatives of this analysis are sufficient to fully describe the genetic diversity of the taxon.

\section{Methods}

\section{Genome sequencing}

All genomes sequenced in this study are dairy isolates of L. lactis subsp. lactis and subsp. cremoris, with the exception of L. lactis subsp. lactis UC08 and UC11, which were isolated from fermented meat products (Table 1). Chromosomal DNA from L. lactis subsp. cremoris JM1, JM2, JM3 and JM4 was isolated as previously described [43]. Chromosomal DNA extraction from L. lactis subsp. cremoris 158, UC109, L. lactis subsp. lactis UC11, C10, UL8 UC08, 275, UC063, UC06 184, 229 and UC77 was performed by commercial sequencing service providers GATC Biotech Ltd. (Germany).

SMRT sequencing was performed on a Pacific Biosciences RS II sequencing platform (executed by GATC Biotech Ltd., Germany). De novo genome assemblies were performed using the Pacific Biosciences SMRTPortal analysis platform (version 2.3.1), utilizing the RS_HGAP_Assembly. 2 protocol. Remaining low quality regions or sequencing conflicts were resolved by primer walking and
Sanger sequencing of PCR products (through sequence service proider Eurofins MWG Operon, (Germany).

\section{General feature predictions}

After final genome assembly, Open Reading Frame (ORF) [or coding sequence (CDS)] prediction was performed with Prodigal v2.5 prediction software [44] and confirmed using BLASTX v2.2.26 alignments [28]. ORFs were automatically annotated using BLASTP v2.2.26 [28] analysis against the non-redundant protein databases curated by the National Centre for Biotechnology Information (NCBI) [45]. Following automatic annotation, ORFs were manually curated using Artemis v16 genome browser and annotation tool [46]. The software tool was used for the combination and inspection of ORF-identification results, for adjustment of start codons (where necessary), and for the identification of pseudogenes. Finally ORF annotations were refined further where required using alternative functional searches using Pfam [47], HHpred [48], PHAST [49] and Uniprot/EMBL [50].

Transfer RNA (tRNA) and ribosomal RNA (rRNA) genes were predicted using tRNA-scan-SE v1.4 [51] and RNAmmer v1.2 [52], respectively. Predicted RNA encoding genes were manually added to each genome using Artemis v16.

\section{Comparative genomics}

The Mauve alignment tool was employed in order to perform whole genome alignments at the nucleotide level, and to explore synteny within the genomes and identify potential integration sites [53]. Genome synteny was explored and dotplots generated using Geopard v1.40 [54]. All sequence comparisons at the protein level were performed via all-against-all, bi-directional BLAST alignments [28]. An alignment cut-off value of; E-value $0.0001,>30 \%$ amino acid identity across $80 \%$ of the sequence length was used. For analysis and clustering of these results, the Markov Clustering Algorithm (MCL) was implemented in the mclblastline pipeline v12-0678 [29]. To further analyse genome-encoded functions, the protein complement was categorised based on COG (clusters of orthologous groups) assignments [55]. Metabolic pathways encoded by L. lactis strains were predicted and mapped using KEGG (Kyoto Encyclopaedia of Genes and Genomes) [56, 57]. Logo motifs were produced using WebLogo 3 [58].

\section{Phylogenetic analysis}

The lactococcal supertree computation was performed by the BLAST-based comparative approach outlined above to identify a subset of 596 orthologous proteins. The subset was concatenated for each strain and an ungapped alignment was performed using MUSCLE 
v3.8.31 [59] with Streptococcus thermophilus LMG 18311 (Accession: CP000023) used as an outgroup. The phylogenetic tree was computed by the maximumlikelihood method in PhyML v3.0 and bootstrapped employing 1000 replicates [60]. The final tree file was visualised using ITOL (Interactive Tree of Life) [61]. 16S rRNA trees were prepared in MEGA6. Alignments were performed using MUSCLE. The evolutionary history was inferred by the Neighbour-joining method [62].

\section{Pan- and core-genome analysis}

For the 30 available lactococcal genomes in this study, PGAP v1.0 [27] was used to perform the pan-genome analysis according to Heaps law pan-genome model [20]. The ORF content of each genome is organised in functional gene clusters via the Gene Family method. ORFs which produce an alignment with a minimum of $50 \%$ sequence identity across $50 \%$ of the gene/protein length are clustered and a pan/core genome profile is subsequently generated. The analysis is performed based solely on sequence identity and is not biased by functional annotation.

\section{Strain growth conditions and media}

Bacterial strains used in this study are detailed in Table 1. L. lactis strains were routinely cultured at $30{ }^{\circ} \mathrm{C}$ in $\mathrm{M} 17$ broth (Oxoid) supplemented with $0.5 \%$ glucose/lactose without agitation. Alternatively strains where indicated, were grown in 10\% RSM (reconstituted skimmed milk) at $30{ }^{\circ} \mathrm{C}$ without agitation.

\section{Intracellular enzymatic assays}

Cells were prepared via a $1.5 \%$ inoculum into $10 \%$ RSM and grown overnight (16 hours) at $30{ }^{\circ} \mathrm{C}$. Cells were then plated on M17 agarose supplemented with lactose to determine a viable plate count in $\mathrm{cfu} / \mathrm{ml} .50 \mathrm{ml}$ of an overnight culture was added to $450 \mathrm{ml}$ of borate buffer (0.05 M EDTA and 0.5 M borate pH8 with $\mathrm{NaOH}$ ) and cells were collected by centrifugation (7000 rpm for $9 \mathrm{~min}$ ). Cells were then washed in imidazole buffer (50 mmol/l imidazole and $10 \mathrm{mmol} / \mathrm{l}$ calcium chloride pH6.5) and pelleted by centrifugation (7000 rpm for $9 \mathrm{~min})$. Cell pellet was re-suspended in $5 \mathrm{ml}$ of lysis buffer $(10 \mathrm{mM}$ Tris-HCL, $50 \mathrm{mM} \mathrm{CaCl} 2,300 \mathrm{mM} \mathrm{NaCl}$, $10 \mathrm{mM}$ imidazole, $25 \mathrm{mg} / \mathrm{ml}$ of lysozyme, pH 7.5). Cells were then sonicated five times (30 s each) with $30 \mathrm{~s}$ on ice in between each sonication, after which cell debris was removed by centrifugation $(15,000 \mathrm{rpm}$ for $25 \mathrm{~min}$ at $4{ }^{\circ} \mathrm{C}$ ). The resulting supernatant was then quantified for peptide/aminotransferase/esterase activity.

Detection of specific peptidase activities was conducted by fluorescence using 7-amino-4-methyl coumarin (AMC) coupled peptidase substrates; H-Lys-AMC.acetate (LysAMC) PepN and PepC, H-Asp (AMC)-OH (Asp-AMC)
PepA, H-Pro-AMC.HBr (Pro-AMC) Proline imino peptidase, H-Gly-Pro-AMC. HBr (Gly-Pro-AMC) PepX, N-SucGly-Pro-Leu-Gly-Pro-AMC (Gly-Pro-Leu-Gly-Pro-AMC) Endopeptidase and CBZ-Gly-Pro-AMC (Z-Gly-Pro-AMC) Carboxypeptidase, sourced from Bachem AG through VWR Ireland. The protocol was performed as described by Kato and colleagues [63], with the exception of reduced volumes for high throughput screening in 96-well plates. Released fluorescence was measured on a SpectraMax M3 Multi-Mode Microplate Reader from Molecular Devices. Enzyme activity was calculated in RFU PPDA (1 RFU = the amount of $\mathrm{uM}$ of AMC released $\mathrm{min}^{-1}$ by $1 \mathrm{mg}$ of protein).

Amino acid transferase activity was determined (for Phe and Met) as previously described by Cavanagh and colleagues [16]. The final absorbance was read at wavelength, $300 \mathrm{~nm}$ in triplicate on a DU Series 730 spectrophotometer from Beckman Coulter, blanking the machine between each measurement. Standard curves were prepared for phenylalanine and methionine using phenylpyruvate and $\alpha$-ketomethylthiobutyrate respectively. Amino acid transferase activity was then expressed as micromoles per minute per milligram of protein.

Detection of short chain esterase activity was conducted via a spectrophotometric assay as previously described [64], utilising $p$-nitrophenyl butyrate as a substrate. Absorbance was measured on a DU Series 730 spectrophotometer from Beckman Coulter. All activities measured were normalised for each strain based on cell count.

\section{Nucleotide sequence accession numbers}

L. lactis subsp. lactis Il1403 AE005176, L. lactis subsp. lactis KF147 CP001834, L. lactis subsp. lactis CV56 CP002365, L. lactis subsp. lactis IO-1 AP012281, L. lactis subsp. lactis KLDS 4.0325 CP006766, L. lactis subsp. lactis NCDO 2118 CP009054, L. lactis subsp. lactis SO CP010050, L. lactis subsp. lactis AI06 CP009472, L. lactis subsp. lactis 184 CP015895, L. lactis subsp. lactis 229 CP015896, L. lactis subsp. lactis 275 CP015897, L. lactis subsp. lactis UC06 CP015902, L. lactis subsp. lactis UC08 CP015903, L. lactis subsp. lactis UC11 CP015904, L. lactis subsp. lactis UC063 CP015905, L. lactis subsp. lactis UC77 CP015906, L. lactis subsp. lactis UL8 CP015908, L. lactis subsp. lactis C10 CP015898, L. lactis subsp. cremoris SK11 CP000425, L. lactis subsp. cremoris MG1363 AM406671, L. lactis subsp. cremoris NZ9000 CP002094, L. lactis subsp. cremoris A76 CP003132, L. lactis subsp. cremoris UC509.9 CP003157, L. lactis subsp. cremoris KW2 CP004884, L. lactis subsp. cremoris 158 CP015894, L. lactis subsp. cremoris UC109 CP015907, L. lactis subsp. cremoris JM1 CP015899, L. lactis subsp. cremoris JM2 CP015900, L. lactis subsp. cremoris JM3 CP015901, L. lactis subsp. cremoris JM4 CP015909 and S. thermophilus LMG 18311 CP000023. 


\section{Additional files}

Additional file 1: Phylogenetic analysis of $L$. lactis housekeeping genes. Unrooted bootstrapped ( $\times 100$ replicates) maximum likelihood trees of; $[\mathrm{A}] \mathrm{rad} A,[\mathrm{~B}] \mathrm{radC},[\mathrm{C}] \mathrm{ssb}, \mathrm{A}, \mathrm{D}] \mathrm{rec} \mathrm{Q}$ and $[\mathrm{E}] \mathrm{rec} X$. Trees are coloured in accordance with subspecies type. (PPTX $116 \mathrm{~kb}$ )

Additional file 2: Whole genome nucleotide dotplots. Whole genome nucleotide alignments of thirty fully sequenced L. lactis genomes. Alignments 1 (red)-18 represent subsp. lactis genomes. Alignments 19(black)-30 represent subsp. cremoris genomes. (PPTX 1744 kb)

Additional file 3: Unique gene family list. List of locus tag identifiers and predicted functions of unique gene families identified by $\mathrm{MCL}$ clustering. (XLSX 24 kb)

Additional file 4: $\mathrm{KEGG}$ ontologies. Overview of the presence or absence of complete intact KEGG modules in Lactococcus. (XLSX 17 kb)

Additional file 5: Plasmid integrations. Table detailing chromosomal regions sharing significant homology to previously sequenced lactococcal plasmids. (XLSX $15 \mathrm{~kb}$ )

Additional file 6: Pearce assay growth curves. Pearce assay growth curves of representative strains; $[A]$ L. lactis subsp. cremoris JM1, [B] L. lactis subsp. cremoris JM4, [C] L. lactis subsp. cremoris JM3, [D] L. lactis subsp. cremoris JM2, [E] L. lactis subsp. lactis 229, [F] L. lactis subsp. lactis UC063, [G] L. lactis subsp. cremoris SK11, [H] L. lactis subsp. cremoris UC109, [1] L. lactis subsp. cremoris 158, [J] L. lactis subsp. lactis UC77, [K] L. lactis subsp. lactis 275, [L] L. lactis subsp. lactis 184. Black lines represent growth under Pearce assay conditions (Temperature: $32{ }^{\circ} \mathrm{C}$ for $70 \mathrm{~min}$, $32-38{ }^{\circ} \mathrm{C}$ for $30 \mathrm{~min}, 38^{\circ} \mathrm{C}$ for $160 \mathrm{~min}, 32^{\circ} \mathrm{C}$ for $40 \mathrm{~min}$ ). Red (subsp. cremoris) and blue (subsp. lactis) lines represent controls grown at $30^{\circ} \mathrm{C}$ for $300 \mathrm{~min}$. (PPTX $96 \mathrm{~kb}$ )

Additional file 7: Multilocus supertree orthologues and 16S rRNA genes list. List of locus tag identifiers and predicted functions of 596 orthologous protein sequences which were concatenated to generate the multilocus supertree and list of locus tag identifiers used to generate the 165 rRNA tree. (XLSX $34 \mathrm{~kb}$ )

\section{Abbreviations}

BLAST: Basic alignment search tool; CDS: Coding sequence; COG: Cluster of orthologous groupings; HCL: Hierarchical clustering; ITOL: Interactive tree of life; MCL: Markov Clustering Algorithm; NGS: Next generation sequencing; ORF: Open Reading Frame; SMRT: Single molecule real time sequencing

\section{Acknowledgements}

Not applicable

\section{Funding}

Philip Kelleher is funded by the Department of Agriculture, Food and the Marine under the Food Institutional Research Measure (FIRM) (Ref: 10/RD/ TMFRC/704-'CheeseBoard 2015' project). Douwe van Sinderen is supported by a Principal Investigator award (Ref. No. 13/IA/1953) through Science Foundation Ireland (SFI). Jennifer Mahony is in receipt of a Technology Innovation Development Award (TIDA) (Ref. No. 14/TIDA/2287) and Starting Investigator Research Grant (15/SIRG/3430) funded by Science Foundation Ireland (SFI).

\section{Availability of data and materials}

All genome sequences used in the course of this study are available from the National Centre for Biotechnology Information, (NCBI) genome database. Additionally, all genomes sequenced during the course of this study have been deposited in the NCBI genome database (Accession numbers: see Methods). List of locus tag identifiers and predicted functions of 596 orthologous protein sequences which were concatenated to generate the multilocus supertree are provided in Additional file 7. List of locus tag identifiers and predicted functions of unique gene families are provided in Additional file 3. List of plasmid integration events and coordinates are provided in Additional file 5.

\section{Authors' contributions}

PK carried out data analysis with FB. PK, FB contributed to sequence assembly and annotation. PK performed experiments. DVS, JM provided materials and strains. KK provided methods \& experimental outlines. PK, JM and DvS wrote the manuscript. All authors read and approved the final manuscript.

\section{Competing interests}

The authors declare that they have no competing interests.

\section{Consent for publication}

Not applicable

\section{Ethics approval}

Ethics approval did not apply in this study since the animal samples from which strains L. lactis UC08 and UC11 were isolated, were sourced as fermented meat products sold commercially as fermented sausage for human consumption. The samples were bought commercially and the strains isolated via homogenization and plating of the product.

\section{Publisher's Note}

Springer Nature remains neutral with regard to jurisdictional claims in published maps and institutional affiliations.

\section{Author details}

${ }^{1}$ School of Microbiology, University College Cork, Cork, Ireland. ${ }^{2}$ Alimentary Pharmabiotic Centre, University College Cork, Cork, Ireland. ${ }^{3}$ Department of Food Biosciences, Teagasc Food Research Centre, Moorepark, Cork, Ireland.

Received: 10 September 2016 Accepted: 21 March 2017

Published online: 29 March 2017

\section{References}

1. Schleifer K, Kilpper-Bälz R. Molecular and chemotaxonomic approaches to the classification of streptococci, enterococci and lactococci: a review. Syst Appl Microbiol. 1987;10:1-19.

2. Latorre-Guzman BA, Kado Cl, Kunkee RE. Lactobacillus hordniae, a New Species from the Leafhopper (Hordnia circellata). Int J Syst Evol Microbiol. 1977:27:362-70

3. Perez T, Balcazar JL, Peix A, Valverde A, Velazquez E, de Blas I, Ruiz-Zarzuela I. Lactococcus lactis subsp. tructae subsp. nov. isolated from the intestinal mucus of brown trout (Salmo trutta) and rainbow trout (Oncorhynchus mykiss). Int J Syst Evol Microbiol. 2011;61:1894-8.

4. Ainsworth S, Stockdale S, Bottacini F, Mahony J, van Sinderen D. The Lactococcus lactis plasmidome: much learnt, yet still lots to discover. FEMS Microbiol Rev. 2014:38:1066-88

5. Chopin A, Bolotin A, Sorokin A, Ehrlich SD, Chopin MC. Analysis of six prophages in Lactococcus lactis IL 1403: different genetic structure of temperate and virulent phage populations. Nucleic Acids Res. 2001;29:644-51.

6. Ainsworth S, Zomer A, de Jager V, Bottacini F, van Hijum SA, Mahony J, van Sinderen D. Complete genome of Lactococcus lactis subsp. cremoris UC509. 9, host for a model lactococcal P335 bacteriophage. Genome Announc. 2013;1:e00119-00112.

7. Makarova K, Slesarev A, Wolf Y, Sorokin A, Mirkin B, Koonin E, Pavlov A, Pavlova N, Karamychev V, Polouchine N. Comparative genomics of the lactic acid bacteria. Proc Natl Acad Sci. 2006;103:15611-6.

8. van Rooijen RJ, De Vos W. Molecular cloning, transcriptional analysis, and nucleotide sequence of $l a c R$, a gene encoding the repressor of the lactose phosphotransferase system of Lactococcus lactis. J Biol Chem. 1990;265:18499-503

9. Van Rooijen R, Gasson M, De Vos W. Characterization of the Lactococcus lactis lactose operon promoter: contribution of flanking sequences and LacR repressor to promoter activity. J Bacteriol. 1992;174:2273-80.

10. Drider D, Bekal S, Prévost H. Genetic organization and expression of citrate permease in lactic acid bacteria. Genet Mol Res. 2004;3:271-81.

11. Kelly WJ, Ward LJH, Leahy SC. Chromosomal diversity in Lactococcus lactis and the origin of dairy starter cultures. Genome Biol Evol. 2010;2:729-44.

12. Bolotin A, Wincker $P$, Mauger S, Jaillon O, Malarme K, Weissenbach J, Ehrlich SD, Sorokin A. The complete genome sequence of the lactic acid bacterium Lactococcus lactis ssp. lactis IL1403. Genome Res. 2001:11:731-53. 
13. Wegmann U, O'Connell-Motherway M, Zomer A, Buist G, Shearman C, Canchaya C, Ventura M, Goesmann A, Gasson MJ, Kuipers OP. Complete genome sequence of the prototype lactic acid bacterium Lactococcus lactis subsp. cremoris MG1363. J Bacteriol. 2007;189:3256-70.

14. Liu M, Nauta A, Francke C, Siezen RJ. Comparative genomics of enzymes in flavor-forming pathways from amino acids in lactic acid bacteria. Appl Environ Microbiol. 2008;74:4590-600.

15. Liu M, Bayjanov J, Renckens B, Nauta A, Siezen R. The proteolytic system of lactic acid bacteria revisited: a genomic comparison. BMC Genomics. 2010;11:36.

16. Cavanagh D, Casey A, Altermann E, Cotter PD, Fitzgerald GF, McAuliffe O. Evaluation of Lactococcus lactis isolates from nondairy sources with potential dairy applications reveals extensive phenotype-genotype disparity and implications for a revised species. Appl Environ Microbiol. 2015;81:3961-72.

17. Siezen RJ, Bayjanov JR, Felis GE, van der Sijde MR, Starrenburg M, Molenaar D, Wels M, van Hijum SA, van Hylckama Vlieg JE. Genome-scale diversity and niche adaptation analysis of Lactococcus lactis by comparative genome hybridization using multi-strain arrays. Microb Biotechnol. 2011;4:383-402.

18. Gupta PK. Single-molecule DNA sequencing technologies for future genomics research. Trends Biotechnol. 2008;26:602-11.

19. McCarthy A. Third generation DNA sequencing: Pacific Biosciences single molecule real time technology. Chem Biol. 2010;17:675-6.

20. Tettelin H, Masignani V, Cieslewicz MJ, Donati C, Medini D, Ward NL, Angiuoli SV, Crabtree J, Jones AL, Durkin AS, DeBoy RT, Davidsen TM, Mora M, Scarselli M, Margarit y Ros I, Peterson JD, Hauser CR, Sundaram JP, Nelson WC, Madupu R, Brinkac LM, Dodson RJ, Rosovitz MJ, Sullivan SA, Daugherty SC, Haft DH, Selengut J, Gwinn ML, Zhou L, Zafar N, Khouri H, Radune D, Dimitrov G, Watkins K, O'Connor KJB, Smith S, Utterback TR, White O, Rubens CE, Grandi G, Madoff LC, Kasper DL, Telford UL, Wessels MR, Rappuoli R, Fraser CM. Genome analysis of multiple pathogenic isolates of Streptococcus agalactiae: Implications for the microbial "pan-genome". Proc Natl Acad Sci U S A. 2005;102:13950-5.

21. Medini D, Donati C, Tettelin H, Masignani V, Rappuoli R. The microbial pan-genome. Curr Opin Genet Dev. 2005;15:589-94.

22. Bottacini F, O'Connell-Motherway M, Kuczynski J, O'Connell KJ, Serafini F, Duranti S, Milani C, Turroni F, Lugli GA, Zomer A, Zhurina D, Riedel C, Ventura $M$, van Sinderen D. Comparative genomics of the Bifidobacterium breve taxon. BMC Genomics. 2014;15:1-19.

23. Mardis E, McPherson J, Martienssen R, Wilson RK, McCombie WR. What is finished, and why does it matter. Genome Res. 2002;12:669-71.

24. Denton JF, Lugo-Martinez J, Tucker AE, Schrider DR, Warren WC, Hahn MW. Extensive error in the number of genes inferred from draft genome assemblies. PLoS Comput Biol. 2014;10:e1003998.

25. De Angelis M, Bottacini F, Fosso B, Kelleher P, Calasso M, Di Cagno R, Ventura M, Picardi E, van Sinderen D, Gobbetti M. Lactobacillus rossiae, a vitamin B12 producer, represents a metabolically versatile species within the genus Lactobacillus. PLoS One. 2014;9:e107232

26. McCulloch JA, de Oliveira VM, de Almeida Pina AV, Perez-Chaparro PJ, de Almeida LM, de Vasconcelos JM, de Oliveira LF, da Silva DE, Rogez HL, Cretenet M, Mamizuka EM, Nunes MR. Complete genome sequence of Lactococcus lactis strain Al06, an endophyte of the Amazonian Acai Palm. Genome Announc. 2014:2.

27. Zhao Y, Wu J, Yang J, Sun S, Xiao J, Yu J. PGAP: pan-genomes analysis pipeline. Bioinformatics. 2012;28:416-8.

28. Altschul SF, Gish W, Miller W, Myers EW, Lipman DJ. Basic local alignment search tool. J Mol Biol. 1990;215:403-10.

29. Enright AJ, Van Dongen S, Ouzounis CA. An efficient algorithm for large-scale detection of protein families. Nucleic Acids Res. 2002;30:1575-84.

30. Solopova A, Bachmann H, Teusink B, Kok J, Neves AR, Kuipers OP. A specific mutation in the promoter region of the silent cel cluster accounts for the appearance of lactose-utilizing Lactococcus lactis MG1363. Appl Environ Microbiol. 2012;78:5612-21.

31. Chopin A, Chopin MC, Moillo-Batt A, Langella P. Two plasmid-determined restriction and modification systems in Streptococcus lactis. Plasmid. 1984;11:260-3.

32. Sybesma W, Starrenburg M, Kleerebezem M, Mierau I, de Vos WM, Hugenholtz J. Increased production of folate by metabolic engineering of Lactococcus lactis. Appl Environ Microbiol. 2003;69:3069-76.

33. McSweeney PLH. Biochemistry of cheese ripening. Int J Dairy Technol. 2004; 57:127-44.

34. Steele J, Broadbent J, Kok J. Perspectives on the contribution of lactic acid bacteria to cheese flavor development. Curr Opin Biotechnol. 2013;24:135-41.

35. Kelleher P, Murphy J, Mahony J, van Sinderen D. Next-generation sequencing as an approach to dairy starter selection. Dairy Sci Technol. 2015;95:545-68.
36. Guédon E, Renault P, Ehrlich SD, Delorme C. Transcriptional pattern of genes coding for the proteolytic system of Lactococcus lactis and evidence for coordinated regulation of key enzymes by peptide supply. J Bacteriol. 2001;183:3614-22.

37. Smit BA, Engels WJM, Wouters JTM, Smit G. Diversity of I-leucine catabolism in various microorganisms involved in dairy fermentations, and identification of the rate-controlling step in the formation of the potent flavour component 3-methylbutanal. Appl Microbiol Biotechnol. 2004;64:396-402.

38. Goh YJ, Goin C, O'Flaherty S, Altermann E, Hutkins R. Specialized adaptation of a lactic acid bacterium to the milk environment: the comparative genomics of Streptococcus thermophilus LMD-9. Microb Cell Fact. 2011;10 Suppl 1:S22.

39. Yu W, Gillies K, Kondo JK, Broadbent JR, McKay LL. Loss of plasmid-mediated oligopeptide transport system in lactococci: Another reason for slow milk coagulation. Plasmid. 1996:35:145-55.

40. Liu Y, Harrison PM, Kunin V, Gerstein M. Comprehensive analysis of pseudogenes in prokaryotes: widespread gene decay and failure of putative horizontally transferred genes. Gen Biol. 2004;5(9):1.

41. Makarova K, Slesarev A, Wolf $Y$, Sorokin A, Mirkin B, Koonin E, Pavlov A, Pavlova N, Karamychev V, Polouchine N, Shakhova V, Grigoriev I, Lou Y, Rohksar D, Lucas S, Huang K, Goodstein DM, Hawkins T, Plengvidhya V, Welker D, Hughes J, Goh Y, Benson A, Baldwin K, Lee JH, Diaz-Muniz I, Dosti B, Smeianov V, Wechter W, Barabote R, Lorca G, Altermann E, Barrangou R, Ganesan B, Xie Y, Rawsthorne H, Tamir D, Parker C, Breidt F, Broadbent J, Hutkins R, O'Sullivan D, Steele J, Unlu G, Saier M, Klaenhammer T, Richardson P, Kozyavkin S, Weimer B, Mills D. Comparative genomics of the lactic acid bacteria. Proc Natl Acad Sci U S A. 2006;103:15611-6.

42. Cavanagh D, Fitzgerald GF, McAuliffe O. From field to fermentation: the origins of Lactococcus lactis and its domestication to the dairy environment. Food Microbiol. 2015;47:45-61.

43. Sambrook J, Russell DW: Purification of nucleic acids by extraction with phenol:chloroform. Cold Spring Harb Protoc. 2006; doi:10.1101/pdb. prot4455.

44. Hyatt D, Chen GL, LoCascio PF, Land ML, Larimer FW, Hauser LJ. Prodigal: prokaryotic gene recognition and translation initiation site identification. BMC Bioinformatics. 2010;11:1-11.

45. National Centre for Biotechnology Information, US. https://www.ncbi.nlm. nig.gov/. Accessed May 2016

46. Wellcome Trust, Sanger Institude. Artemis Genome Browser. http://www. sanger.ac.uk/science/tools/artemis.

47. Bateman A, Coin L, Durbin R, Finn RD, Hollich V, Griffiths-Jones S, Khanna A, Marshall M, Moxon S, Sonnhammer EL. The Pfam protein families database. Nucleic Acids Res. 2004;32:D138-41

48. Söding J, Biegert A, Lupas AN. The HHpred interactive server for protein homology detection and structure prediction. Nucleic Acids Res. 2005;33:W244-8.

49. Zhou Y, Liang Y, Lynch KH, Dennis JJ, Wishart DS: PHAST: a fast phage search tool. Nucleic Acids Res. 2011, doi:10.1093/nar/gkr485.

50. Uniprot database. http://www.uniprot.org/. Accessed May 2016.

51. Schattner P, Brooks AN, Lowe TM. The tRNAscan-SE, snoscan and snoGPS web servers for the detection of tRNAs and snoRNAs. Nucleic Acids Res. 2005:33(Web Server issue):W686-9.

52. Lagesen K, Hallin P, Rodland EA, Staerfeldt HH, Rognes T, Ussery DW. RNAmmer: consistent and rapid annotation of ribosomal RNA genes. Nucleic Acids Res. 2007;35(9):3100-8.

53. Darling AC, Mau B, Blattner FR, Perna NT. Mauve: multiple alignment of conserved genomic sequence with rearrangements. Genome Res. 2004; 14:1394-403.

54. Krumsiek J, Arnold R, Rattei T. Gepard: a rapid and sensitive tool for creating dotplots on genome scale. Bioinformatics. 2007;23:1026-8.

55. Tatusov RL, Galperin MY, Natale DA, Koonin EV. The COG database: a tool for genome-scale analysis of protein functions and evolution. Nucleic Acids Res. 2000;28:33-6.

56. Kanehisa M, Goto S. KEGG: kyoto encyclopedia of genes and genomes. Nucleic Acids Res. 2000;28:27-30.

57. Kanehisa M, Sato Y, Kawashima M, Furumichi M, Tanabe M. KEGG as a reference resource for gene and protein annotation. Nucleic Acids Res. 2016;44:D457-62.

58. Crooks GE, Hon G, Chandonia JM, Brenner SE. WebLogo: a sequence logo generator. Genome Res. 2004;14:1188-90. 
59. Edgar RC. MUSCLE: multiple sequence alignment with high accuracy and high throughput. Nucleic Acids Res. 2004;32:1792-7.

60. Guindon S, Gascuel O. A simple, fast, and accurate algorithm to estimate large phylogenies by maximum likelihood. Syst Biol. 2003;52:696-704.

61. Letunic I, Bork P. Interactive tree of life (iTOL) v3: an online tool for the display and annotation of phylogenetic and other trees. Nucleic Acids Res. 2016;44:W242-5.

62. Saitou N, Nei M. The neighbor-joining method: a new method for reconstructing phylogenetic trees. Mol Biol Evol. 1987;4:406-25.

63. Kato T, Nagatsu T, Kimura T, Sakakibara S. Fluorescence assay of X-prolyl dipeptidyl-aminopeptidase activity with a new fluorogenic substrate. Biochem Med. 1978;19:351-9.

64. Vorderwülbecke T, Kieslich K, Erdmann H. Comparison of lipases by different assays. Enzyme Microb Technol. 1992;14:631-9.

65. Siezen RJ, Bayjanov J, Renckens B, Wels M, van Hijum SA, Molenaar D, van Hylckama Vlieg JE. Complete genome sequence of Lactococcus lactis subsp. lactis KF147, a plant-associated lactic acid bacterium. J Bacteriol. 2010;192:2649-50

66. Gao Y, Lu Y, Teng KL, Chen ML, Zheng HJ, Zhu YQ, Zhong J. Complete genome sequence of Lactococcus lactis subsp. lactis CV56, a probiotic strain isolated from the vaginas of healthy women. J Bacteriol. 2011;193:2886-7.

67. Kato H, Shiwa Y, Oshima K, Machii M, Araya-Kojima T, Zendo T, Shimizu-Kadota M, Hattori M, Sonomoto K, Yoshikawa H. Complete genome sequence of Lactococcus lactis IO-1, a lactic acid bacterium that utilizes xylose and produces high levels of L-lactic acid. J Bacteriol. 2012;194:2102-3.

68. Yang $X$, Wang Y, Huo G. Complete genome sequence of Lactococcus lactis subsp. lactis KLDS4. 0325. Genome Announc. 2013;1:e00962-00913.

69. Oliveira LC, Saraiva TD, Soares SC, Ramos RT, Sá PH, Carneiro AR, Miranda F, Freire M, Renan W, Júnior AF. Genome sequence of Lactococcus lactis subsp. lactis NCDO 2118, a GABA-producing strain. Genome Announc. 2014;2: e00980-00914.

70. Zhao F, Ma H, Lu Y, Teng K, Kang X, Wang F, Yang X, Zhong J. Complete genome sequence of Lactococcus lactis SO, an efficient producer of nisin. J Biotechnol. 2015;198:15-6.

71. Linares DM, Kok J, Poolman B. Genome sequences of Lactococcus lactis MG1363 (revised) and NZ9000 and comparative physiological studies. J Bacteriol. 2010;192:5806-12.

72. Bolotin A, Quinquis B, Ehrlich SD, Sorokin A. Complete genome sequence of Lactococcus lactis subsp. cremoris A76. J Bacteriol. 2012:194:1241-2.

73. Kelly WJ, Altermann E, Lambie SC, Leahy SC. Interaction between the genomes of Lactococcus lactis and phages of the P335 species. Front Microbiol. 2013;4:257.

\section{Submit your next manuscript to BioMed Central and we will help you at every step:}

- We accept pre-submission inquiries

- Our selector tool helps you to find the most relevant journal

- We provide round the clock customer support

- Convenient online submission

- Thorough peer review

- Inclusion in PubMed and all major indexing services

- Maximum visibility for your research

Submit your manuscript at www.biomedcentral.com/submit 